NBER WORKING PAPER SERIES

\title{
THE SHADOW MARGINS OF LABOR MARKET SLACK
}

\author{
R. Jason Faberman \\ Andreas I. Mueller \\ Ayşegül Şahin \\ Giorgio Topa \\ Working Paper 26852 \\ http://www.nber.org/papers/w26852 \\ NATIONAL BUREAU OF ECONOMIC RESEARCH \\ 1050 Massachusetts Avenue \\ Cambridge, MA 02138 \\ March 2020
}

We thank our editors Antoine Martin and Ken West, our discussant Marianna Kudlyak, two anonymous referees, and conference participants at the JMCB 50th Anniversary Conference for their comments. Ali Ismail and Jin Yan provided excellent research assistance. The views expressed in this paper are our own and do not necessarily reflect the views of the Federal Reserve Banks of Chicago or New York or the Federal Reserve System. The views expressed herein are those of the authors and do not necessarily reflect the views of the National Bureau of Economic Research.

NBER working papers are circulated for discussion and comment purposes. They have not been peer-reviewed or been subject to the review by the NBER Board of Directors that accompanies official NBER publications.

(C) 2020 by R. Jason Faberman, Andreas I. Mueller, Ayşegül Şahin, and Giorgio Topa. All rights reserved. Short sections of text, not to exceed two paragraphs, may be quoted without explicit permission provided that full credit, including $\left({ }^{\circ}\right.$ notice, is given to the source. 
The Shadow Margins of Labor Market Slack

R. Jason Faberman, Andreas I. Mueller, Ayşegül Şahin, and Giorgio Topa

NBER Working Paper No. 26852

March 2020

JEL No. E24,J21,J60

\begin{abstract}
$\underline{\text { ABSTRACT }}$
We use a mix of new and existing data to develop the Aggregate Hours Gap (AHG), a novel measure of labor market underutilization. Our measure differentiates individuals by detailed categories of labor market participation and uses data on their desired work hours as a measure of their potential labor supply. We show that desired hours vary widely by demographics and detailed labor force status, and that the gap between desired and actual work hours is strongly positively correlated with reported search effort. The Aggregate Hours Gap suggests a more sluggish labor market recovery since the Great Recession than either the official unemployment rate or alternative measures of labor market underutilization. Modest amounts of underutilization among the part-time employed and a substantial degree of underutilization among those out of the labor force account for the disparity. The Aggregate Hours Gap also does well in accounting for wage movements over our sample period.
\end{abstract}

R. Jason Faberman

Economic Research Department

Federal Reserve Bank of Chicago

230 S. LaSalle St.

Chicago, IL 60604

jfaberman@frbchi.org

Andreas I. Mueller

The University of Texas at Austin

Department of Economics

2225 Speedway

Austin, TX 78712

and NBER

andimueller@utexas.edu

\author{
Ayşegül Şahin \\ Department of Economics \\ University of Texas at Austin \\ 2225 Speedway \\ Austin, TX 78712 \\ and NBER \\ aysegul.sahin@austin.utexas.edu \\ Giorgio Topa \\ Federal Reserve Bank of New York \\ Research \& Statistics Group \\ 33 Liberty Street \\ New York, NY 10045 \\ giorgio.topa@ny.frb.org
}




\section{Introduction}

A fundamental question in macroeconomics is how to best assess the degree of labor market slack, or underutilization, in the broader economy. Timely measures of labor market underutilization are one of the most important inputs for monetary policy decisions, and measures of the overall health of the labor market are key for government budget projections and fiscal policy decisions. In this paper, we develop an aggregate measure that encompasses all possible margins of labor market underutilization. We show that this measure exhibits notable deviations from the unemployment rate following the Great Recession and it performs relatively well in accounting for wage fluctuations over time.

Historically, economists and policymakers have focused on the unemployment rate as their primary measure of labor market underutilization. It measures the fraction of the labor force that does not have a job but is actively searching for one. While the unemployment rate is a very useful indicator, it has various shortcomings. First, individuals who do not meet the official government definition of unemployed may nevertheless represent labor market underutilization. For example, individuals may give up on job search due to discouragement. These workers are marginally attached to the labor force and research shows that their movements between labor force participation and non-participation vary with the business cycle (Hornstein, Kudlyak, and Lange, 2014; Elsby, Hobijn, and Şahin, 2015; Kudlyak and Lange, 2017). Second, the distribution of the unemployed affects the degree of labor market underutilization. The long-term unemployed have a lower probability of finding work than the short-term unemployed, all else equal, though the causes of this duration dependence are under debate. Recent research also argues that treating the long-term unemployed the same as other unemployed individuals can overstate the degree of labor market underutilization because they are only loosely attached to the labor force (Krueger, Cramer, and Cho, 2014). Third, the unemployment rate does not capture the job search and job-finding behavior of the employed. We know from published statistics that many workers are employed only part-time for economic reasons. These individuals are underemployed, and consequently represent a form of underutilization. Fourth, a key implication of models with on-the-job search is the notion of a wage ladder. Employed 
individuals look for work, receive job offers, and accept those that dominate their current job. Several studies suggest that this process can exert significant wage pressures on the labor market (e.g., Faberman and Justiniano, 2015; Karahan et al., 2017). When labor demand weakens, it reduces the ability of the employed to move up the wage ladder (e.g., Moscarini and Postel-Vinay, 2016; Eeckhout and Lindenlaub, 2019). Published statistics suggest that over half of all hires occur directly from employment, and in earlier research (Faberman et al., 2017), we find that over 20 percent of the employed search for work in a given month. Thus, the employed can represent a degree of labor market underutilization that is relevant for policy decisions as well. ${ }^{1}$ Finally, counts of the number of job seekers, unemployed or otherwise, fail to capture heterogeneity in their desired labor supply. Not all individuals seeking work are looking for the same types of jobs, and those who are already employed may prefer work with hours that differ considerably from their current hours. In short, the unemployment rate captures only a fraction of the potential slack in the labor market.

A useful approach followed in the literature is to assess labor market underutilization by comparing the unemployment rate to a time-varying natural rate of unemployment which is estimated using detailed data on demographics and wage and price inflation, such as in Crump et al (2019). A second approach is to develop broader measures which potentially take into account additional margins of labor market underutilization such as the U4, U5, and U6 measures developed and published by the Bureau of Labor Statistics. However, even these broader measures that incorporate those marginally attached to the labor force or those part-time for economic reasons may fail to capture cyclical variations in total hours since they abstract from hours variation. In response, we develop the Aggregate Hours Gap (AHG), a more comprehensive measure that accounts for cyclical variation in hours across a wide range of labor market behavior. In this sense, we follow a growing list of studies focused on broader measures of labor market underutilization going back to at least Perry (1970). Our measure focuses on the difference between

\footnotetext{
${ }^{1}$ In a series of papers, Bell and Blanchflower (2011, 2013, 2018a, 2018b) use data on preferred hours among the employed to show that underemployment is pervasive across a broad range of the employed, and not necessarily just the part-time employed.
} 
potential labor supply and hours worked in the labor market. We measure potential labor supply using selfreported desired work hours from a survey of individuals we developed in earlier work (Faberman et al., 2017) as a supplement to the Survey of Consumer Expectations (SCE) of the Federal Reserve Bank of New York. The framework through which we consider desired hours is the simple textbook model of aggregate labor supply and labor demand. The aggregate number of hours that households are willing to supply reflect the potential aggregate labor supply. If wages cannot immediately adjust to shocks to labor demand or labor supply, or if there are frictions in the search and hiring process, individuals will be pulled off their labor supply curves, generating a gap between the hours they desire to work and the hours actually work in the economy. It is this notion of slack that our measure of labor market underutilization attempts to estimate.

Before constructing our AHG measure, we provide a detailed analysis of the desired and actual hours and other labor market outcomes by labor force status and demographic characteristics. We categorize individuals by detailed labor force status, differentiating the employed by whether they work full-time or part-time and whether they have one job or multiple jobs; differentiating the unemployed by their duration; and differentiating those out of the labor force by whether they want work, are retired, or out of the labor force for other reasons. Since our supplement is only administered annually, we also look at monthly transitions between different labor force states in the Current Population Survey (CPS). The CPS data also go back much further than the SCE data and are the source for the official measure of the U.S. unemployment rate and other labor market indicators.

We show that search effort, labor market transitions, and desired work hours vary considerably across our more detailed labor force states. Among the employed, part-time workers and multiple jobholders are much less likely than those holding a single, full-time job to remain in their labor market state and they exert more job search effort than other workers do. Transitions to and from multiple jobholding are also surprisingly frequent. As is well known, the long-term unemployed are less likely to find work compared to the short-term unemployed, and conditional on finding work, they are more likely to transition to part-time rather than full-time work, though desired hours and search effort are roughly comparable for the short-term and long-term unemployed. Those who are out of the labor force but want 
work are a highly fluid group. Nearly as many of them transition to other nonparticipation categories as enter the labor force (primarily into unemployment), and less than a third remain in their current state from month to month. By definition, only a fraction of them actively search for work, but their desired work hours are not much less than the desired hours of the unemployed. Others who are out of the labor force, the retired in particular, tend to remain in their current labor market state, exert little to no search effort, but tend to prefer non-negligible work hours if they were to reenter the labor force.

Our measure of desired hours also shows considerable variation by demographics. Men prefer more work hours than women, younger and prime-age workers prefer more work hours than those 55 and older, and desired work hours increase with education, though their differences conditional on labor force status are more nuanced. One may worry that desired work hours reflect cheap talk rather than a true desire to work, particularly among those out of the labor force. In an exercise to validate desired work hours as a measure of potential labor supply, however, we show that there is a clear, positive relationship between search effort and desired hours worked reported in the SCE data. This holds overall and within broad labor force states.

We then move to the development of the Aggregate Hours Gap. We match predicted estimates of desired work hours from the SCE that are based on detailed labor force status and broad demographic categories to individuals in the CPS. We estimate individual hours gaps in the CPS as the difference between the desired hours estimate and their reported work hours. We aggregate these gap measures and interact them with the population shares of each detailed labor force state for each month. The AHG is the resulting weighted sum of the desired hours gaps divided by a weighted sum of desired hours alone (i.e., our measure of potential labor supply). The measure varies over time due to changing population shares and due to changes in desired hours gaps across the detailed labor force states. Therefore, the AHG captures cyclical fluctuations in labor demand as well as trend movements in the desire to work. It also has the appealing 
feature that it measures underutilization in terms of hours rather than bodies and can easily be used as a direct input in potential output calculations, which require estimating potential hours in the economy. ${ }^{2}$

The AHG suggests a substantially slower decline in labor market underutilization following the Great Recession than the unemployment rate. This is not the case during the previous two expansions. Much of this sluggishness is due to an elevated level of labor market underutilization among those out of the labor force that remains high following the end of the Great Recession. Given that much of the elevated sluggishness is driven by increased contributions by retirees and others out of the labor force, we also develop an estimate of underutilization that captures changes due to demographic trends alone. We find that underutilization due to demographics was fairly stable between 1994 and 2007 but has risen steadily and considerably since then.

Finally, we evaluate how our measure performs in predicting wage growth. The ability to identify the component of labor market underutilization that has the greatest effect on aggregate wages is vital to the Phillips curve relationships that dominate most monetary policy decision-making. In national-level regressions, the AHG measure outperforms the unemployment rate in predicting nominal wage growth during our sample period, and performs as well as comparable measures of underutilization, such as the Nonemployment Index developed by Hornstein, Kudlyak, and Lange (2014). We also show that, across U.S. states, the AHG measure paints a very different picture of how state labor markets have recovered following the Great Recession, with many states exhibiting a large drop in their unemployment rate but little to no movement in our estimate of labor market underutilization. At the state level, where we exploit a more robust level of time-series variation within states, the AHG measure does at least as well as the unemployment rate in accounting for nominal wage movements within states over time. Finally, both our national-level and state-level results imply that the employment component of our AHG measure exerts the strongest downward pressure on nominal wage growth. This suggests that the wage ladder channel of aggregate wage dynamics, highlighted by Faberman and Justiniano (2015), Karahan et al. (2017), Moscarini

\footnotetext{
${ }^{2}$ See for example Shackleton (2018) for the CBO's methodology in estimating potential output.
} 
and Postel-Vinay (2016, 2019), Eeckhout and Lindenlaub (2019), Faccini and Melosi (2019), among others, is an important facet of the wage-Philipps curve relationship.

The next section describes the conceptual underpinnings of our AHG measure. Section 3 describes our data and methodology for measuring labor force status, desired work hours, and search behavior. Section 4 presents our motivating evidence on labor market transitions, search effort, and desired work hours by detailed labor force status. Section 5 presents the methodology and results for the AHG measure, including our methodology for measuring its demographic trend. Section 6 evaluates the performance of our underutilization measure in predicting wage pressures. Section 7 concludes.

\section{The Aggregate Hours Gap as a Measure of Underutilization}

Fundamentally, any measure of labor market underutilization is defined as

$$
\frac{\text { Gap }_{t}}{\text { Labor Supply }} \text {. }
$$

For example, consider the official (U3) measure of the BLS unemployment rate. It is equal to the number of unemployed divided by the total labor force. The gap is the number of people who want a job and have actively looked for one (and are available). ${ }^{3}$ Total labor supply is measured as the number of people who either have a job or want a job, i.e., the labor force, which equals total employed and unemployed. This notion of underutilization also holds for the BLS “Alternative Measures of Labor Market Underutilization,” i.e., its "U6" measure of underutilization. For the U6 measure, the gap includes all unemployed plus all those who are "marginally attached" to the labor force but not actually a part of it and those who report that they are part-time rather than full-time for economic reasons. Both measures implicitly give all of these individuals a weight of one when calculating their contribution to labor market underutilization and ignore the variation along the intensive margin of hours.

\footnotetext{
${ }^{3}$ Temporary layoffs fit this notion of a gap, too, because they would otherwise be working their usual hours if they were not on layoff, regardless of their search effort.
} 
The Aggregate Hours Gap that we develop in this paper fits with the notion of underutilization in (1) as well. More specifically, we define our measure of underutilization (or slack) as follows:

$$
S_{t}=\frac{\sum\left(L_{i t}-h_{i t}\right)}{\sum L_{i t}}
$$

Its denominator is a measure of potential labor supply that aggregates the total amount of desired work hours at time $t, \sum L_{i t}$, across all individuals $I$, regardless of their labor force status. Its numerator is a measure of the desired hours gap, $\sum\left(L_{i t}-h_{i t}\right)$, which captures the difference between desired work hours and actual work hours, $h_{i t}$, and sums this difference across all individuals, regardless of their labor force status. Individuals who are non-employed but wish to work add to labor market underutilization based on the amount of hours they prefer to supply. Those who are employed but prefer more work hours add to underutilization based on the difference between their current and preferred hours. Consequently, measures of desired and actual work hours are critical for our estimation of the Aggregate Hours Gap. As we show below, additional information on individuals' demographic characteristics and how they transition across labor market states is informative about their desired hours, and their search behavior is strongly related to their reported desired hours. Thus, our measure has an intuitive interpretation as a measure of labor market underutilization, and our empirical evidence suggests that our direct measure of desired hours is a valid measure of labor supply. Therefore, the AHS can be used as a direct input to potential output calculations.

\section{Data and Measurement}

We use two data sources for our analysis. The first is the Current Population Survey (CPS). The CPS is the survey used to calculate the official U.S. unemployment rate and related labor force statistics. We use the monthly data back to $1994 .{ }^{4}$ We estimate the share of the total population within detailed labor force states and measure desired hours gaps within each labor force state using the monthly CPS data.

\footnotetext{
${ }^{4}$ We only go back to 1994 because it is difficult to produce a consistent measure of our detailed labor force categories, particularly for those out of the labor force, prior to the 1994 CPS redesign.
} 
Our second data source is the Job Search supplement to the Survey of Consumer Expectations (SCE) administered by the Federal Reserve Bank of New York. We developed this supplement in earlier work (see Faberman et al., 2017) and have administered it annually each October since 2013. The labor supplement asks a broad range of questions on one's current employment state, job search activity, employment history, and work preferences (e.g., reservation wage, desired work hours). These include many questions that are comparable to those in the CPS, allowing us to directly measure variables related to labor force status, hours worked, and other characteristics important for our analysis identically across both data sets. Our SCE sample spans 2013 through 2018.

We focus on a sample of individuals aged 18 to 79 with non-missing data on labor force status and broad demographics (age, gender, education) since these are the individuals we can observe in both the SCE and CPS. The CPS is a fairly large sample of about 60,000 households per month. The SCE, however, is much smaller. The Job Search supplement averages just under 1,200 respondents per year. We use a sample that pools individuals across all survey years to generate estimates of the labor market measures described below.

We divide individuals into one of nine labor force states. Four of these represent the employed, and we distinguish them by whether they are part-time or full-time, and within each of these categories, whether or not they are a multiple jobholder. We define the unemployed based on the standard CPS definition (those who want work, have actively searched, and are available for work, plus those on temporary layoff), and distinguish them by whether they are short-duration job seekers (looking for 6 months or less) or longduration job seekers (looking for more than 6 months). Finally, we distinguish those out of the labor force by whether they state wanting work (but otherwise fail to meet the criteria for unemployment), are retired, or are out of the labor force for some other reason (disabled, attending school, or otherwise not working or not wanting work).

Among the employed, we measure hours worked in both the CPS and SCE as total usual hours worked across all jobs. Just under 8 percent of individuals report that their "hours vary" in the CPS. We follow the methodology in Mueller (2017) to impute an hours estimate for them. 
Our desired hours measure comes from the SCE job search supplement. Specifically, the survey question asks,

"Assuming you could find suitable/additional work, how many hours PER WEEK would you prefer to work on this new job?"

The survey only asks this question to individuals who responded that they actively looked for work or stated that they would or "might" take a job if offered to them. For those who consequently do not have a response, we assign them their total current hours if they are employed and zero hours if they are out of the labor force. We do this on the assumption that, for each group, their current hours equal their desired hours since they have not exerted any effort to change their work situation and would not accept any offer of a different work situation. These adjustments impute a zero desired hours gap to these individuals.

We also derive measures of search behavior for individuals from the SCE job search supplement. We identify those who actively searched as those who stated that they looked for work using active search methods (as defined by the CPS, since they are measured in an identical manner in the SCE) or had sent at least one job application in the last four weeks. In the survey, we can further identify whether individuals were looking for new or additional work, and whether they were looking for full-time or part-time work. Finally, we have direct measures of search effort, including the number of applications sent in the last four weeks and the number of hours spent searching in the previous seven days.

\section{Search Behavior, Labor Market Transitions, and Desired Work Hours}

\subsection{Search Behavior and Labor Market Transitions}

We begin our analysis with a study of monthly transition rates across our nine detailed labor force states. Table 1 reports population shares, job-finding rates, and transition rates across labor force states for all individuals in the CPS, averaged across all months from January 1994 to December 2018. The table shows that the transition rates often estimated across the three broad labor force states in the literature (employed, unemployed, or out of the labor force) fail to capture considerable heterogeneity in labor market 
transitions within their categories. For example, we find that 1.2 percent of the employed transition to unemployment, and another 2.5 percent transition out of the labor force, on average. This, however, masks the fact that transition rates out of employment are considerably higher for part-time workers, particularly for part-time workers with only one job. Among those with a single part-time job, 2.4 percent enter unemployment and another 7.3 percent leave the labor force. It also masks the considerable transitions within the labor force states. The table shows that 98.8 percent of full-time workers with multiple jobs remain employed, but only 64.4 percent of them continue to do so as full-time multiple jobholders. Over 28 percent of them transition to a single, full-time job, while another 6.2 percent transition to part-time work. Part-time workers and multiple jobholders have considerably higher job-to-job transition rates than full-time and single jobholders, but transitions into multiple jobholding by single jobholders are notable as well, with about 1.2 percent of full-time workers and 2.1 percent of part-time workers becoming multiple jobholders in any given month. ${ }^{5}$

The heterogeneity among the unemployed is well documented in numerous other studies - the long-term unemployed are considerably less likely to transition to employment and more likely to transition out of the labor force than the short-term unemployed. Among the unemployed that leave the labor force, less than half continue to report wanting work. The heterogeneity among those out of the labor force is not as well known. Returning to Table 1, we find that 65.4 percent of those who are out of the labor force but want work remain out of the labor force, but the majority no longer report wanting work (instead identifying as out of the labor force for other reasons) in the subsequent month. At the same time, these individuals are much more likely to transition to either employment or unemployment than others who report being out of the labor force. The majority of those out of the labor force in our sample are retired, and consistent with their status are the least likely to transition back to the labor force. When they do, they primarily enter as part-time workers.

\footnotetext{
${ }^{5} \mathrm{We}$ analyze job-to-job transitions among the employed further in the appendix and show that job-finding rates for single jobholders are about 60 percent higher when we account for jobs added as an additional job (rather than a switch to a new main job).
} 
Next, we examine how individual search behavior varies by our more detailed labor force status definitions using the SCE job search supplement. The supplement has multiple questions on the incidence, intensity, and scope of one's job search behavior. We analyze search behavior in a similar manner to earlier work (Faberman et al., 2017), but over a longer time horizon (2013-18) and for our nine detailed labor force states.

Our estimates are in Table 2. On average, about 21 percent of the employed engage in on-the-job search, but part-time workers are more likely to look for work than full-time workers and multiple jobholders are more likely to look for work than single jobholders. Part-time workers also exert about twice as much search effort as full-time workers. This holds regardless of whether we measure search effort as the number of applications sent over the previous four weeks or as the number of hours spent searching over the last seven days. ${ }^{6}$ Conditional on actively looking for work, a surprisingly large fraction of the employed are only looking for additional work, with no desire to leave their current (main) job. About onethird of all employed report only looking for an additional job, though this varies widely by employment status. Part-time workers are considerably more likely to seek only additional work, and multiple jobholders are considerably more likely than single jobholders to seek only additional work. Consequently, just under 29 percent of full-time, single jobholders engaging in search only want an additional job, while 66 percent of part-time, multiple jobholders engaging in search only want an additional job. About 23 percent of the employed are only looking for part-time work. Single jobholders and (already) part-time workers are the most likely to only look for part-time work, but the differences by employment status are not notably large or statistically significant.

By definition, nearly all unemployed search (the exception being those on temporary layoff). They also tend to exert relatively high search intensity, sending nine times as many job applications and spending ten times as many hours on search as the employed. A relatively low fraction of the unemployed (about 15 percent) is only looking for part-time work. Only about 18 percent of those who are out of the labor force

\footnotetext{
${ }^{6}$ We measure average search effort across all individuals within each group, including those who report zero job applications sent or zero hours spent searching for work.
} 
but want work actively searched. This is partly by definition since those who are additionally available for work would count as unemployed. Another 35 percent of this group report engaging in no search but would take a job if offered to them. ${ }^{7}$ This is by far the highest share of individuals who respond positively to this question. At the same time, the two estimates combined suggest that 47 percent of those out of the labor force who report wanting work have neither looked for work nor would take a job if offered. While this seems inconsistent with most individuals' concept of "wanting work," it is consistent with the wide-ranging labor force transitions observed for this group in Table 1. Overall, their search effort is comparable to the full-time employed, and among those who want work that did search, less than 9 percent are only looking for part-time work. The search behavior of the retired is quite different. Only 5 percent report actively searching for work, and only an additional 2.6 percent would take a job if offered. Their search effort is practically non-existent, and for those that do engage in search, the vast majority (72 percent) are only looking for part-time work. About 11 percent of those out of the labor force for other reasons engage in job search, and additional 4 percent would take a job if offered. They exert higher search effort than the retired, but lower effort than all other groups. Just under half of them who search are only seeking part-time work. In summary, there is considerable heterogeneity in search behavior across our detailed labor force states. Taken together, the evidence in Tables 1 and 2 suggests that our more detailed labor force categories contain valuable information on differential labor market outcomes, differential job search behavior, and potentially differential degrees of labor market slack.

\subsection{Evidence on Desired Work Hours}

Next, we examine how actual and desired hours, as well as actual and reservation wages, vary by labor force status and broad demographic group. Our estimates come from the sample of respondents to our SCE Job Search supplement pooled over its 2013-18 surveys. Table 3 reports averages of desired hours,

\footnotetext{
${ }^{7}$ Note that those who report that they "would" take a job if offered is a subset of those who report that they "might" accept a job offer (depending on the circumstances). The latter group represents the scope for respondents asked about their desired work hours. About 69 percent of those out of the labor force but want work say they "might" take a job if offered.
} 
the adjusted gap between desired hours and actual hours worked, total hours worked across all jobs, total hours worked on one's main job, the hourly wage of the main job, and the self-reported reservation wage for our nine detailed labor forces states. ${ }^{8}$ We report an adjusted hours gap for the employed that has a lower bound of zero for individuals who report desired hours that are less than their current work hours. We do this here and in the creation of the AHG measure to ensure that these individuals do not contribute negatively to our estimates of labor market slack, especially since our validation exercise below suggests that their additional work hours may be the result of slack. ${ }^{9}$ Note that, by construction, the nonemployed have zero work hours. Therefore, their hours gap is equal to their desired hours.

Table 3 shows that there are considerable differences, with some notable similarities, in desired work hours, actual work hours, and wages by detailed labor force status. Not surprisingly, full-time workers tend to prefer a full-time level of hours (i.e., more than 35 hours per week), while part-time workers prefer less than full-time hours. Multiple jobholders prefer slightly higher hours than single jobholders, though the differences are not particularly large, especially when compared to the differences in total hours worked between single and multiple jobholders. Multiple jobholders also earn lower hourly wages, on average, than single jobholders. Full-time workers have close to no gap between their desired and actual work hours. Part-time workers with a single job wish to work four more hours than they currently do, on average, and part-time workers with more than one job prefer to work about 1.3 hours more than they do at their current jobs, on average. Across all employment states, average reservation wages exceed average current wages. ${ }^{10}$

\footnotetext{
${ }^{8}$ The survey only asks a reservation wage of respondents who state that they searched for work or would be willing to take a job if offered. Therefore, the reported averages are only for this subset within each group.

${ }^{9}$ Negative hours gaps are most prevalent for multiple jobholders. Shishko and Rostker (1976) show how this situation can reflect labor market slack when an individual cannot find work at her desired labor supply in their main job and the wage of their additional job is lower than that of the main job. Moreover, in a series of studies, Bell and Blanchflower (2011, 2013, 2018a, 2018b) document a pervasive amount of negative hours gaps (which they term as "overemployment") reported in the U.K. Labor Force Survey, and in their more recent work, they document that both negative and positive hours gaps are associated with lower levels of well-being. Thus, our adjustment likely understates the degree of slack in the labor market.

${ }^{10}$ Krueger and Mueller (2016) find, however, that individuals often take jobs that pay below their stated reservation wage. See also Hall and Mueller (2018), who show that this pattern is explained by the presence of non-wage amenities.
} 
Perhaps surprisingly, both the short-term and long-term unemployed prefer full time work, on average, and their desired hours are not significantly different from the desired work hours of those who are full-time employed. Their reservation wages, however, are much lower. In addition, those who are out of the labor force but state that they want work do not look that different from the unemployed. They prefer about 29 hours of work, on average, and their average reservation wage is comparable to that of the longterm unemployed. The retired, on the other hand, look quite different than those in the labor force. They prefer only 11.0 hours of work, on average, and their reservation wage is not significantly different from that of the part-time employed. The remainder of those out of the labor force, which includes students who may plan to enter the labor force soon, the disabled, and others who have chosen not to search, prefer somewhat higher hours than the retired (15.1 hours per week, on average), but have a reservation wage that is comparable to the unemployed and those who want work but are out of the labor force.

Given the wide heterogeneity across labor force states in the desired hours gap, one may wonder if there is considerable heterogeneity within labor force states as well. Figure 1 plots histograms for the distribution of the hours gap for each of the nine detailed labor force states. We report the distribution of the unadjusted hours gaps to highlight the extent that negative hours gaps exist prior to our adjustment for each of the four employment states. ${ }^{11}$ The histograms plot the hours gaps within broad categories with separate bins for those who have a zero gap (i.e., desired hours equal to actual hours) and those whose gap is the equivalent to a full-time job (i.e., 35 hours or more). The figure shows that a sizable fraction of the employed prefer to work less than their current work hours. This is true for about 40 percent of the fulltime employed at a single job and is particularly true for multiple jobholders regardless of full-time/parttime status. Nearly three-quarters of full-time workers with more than one job prefer fewer than their current hours and almost 40 percent of those who are part-time with more than one job would prefer to work less. At the same time, at least half of those with a single job, both full-time and part-time workers, report no gap between their desired and actual work hours. Just under half of part-time workers with multiple jobs

\footnotetext{
${ }^{11}$ We also report the histograms of the adjusted hours gaps by detailed labor force state in the appendix.
} 
also report an hours gap of zero. The employed also rarely prefer to work more hours than they currently do. The notable exception is part-time workers with a single job-35 percent prefer more hours than they currently work, with 26 percent preferring at least 6 more hours of work per week.

Figure 1 also shows that the overwhelming majority of the unemployed prefer full-time work of at least 35 hours. Over 70 percent of both the short-term and long-term unemployed prefer full-time work. Almost all of the remaining unemployed are looking for at least 20 hours of work per week. Those who are out of the labor force but want work also seek out jobs with considerable work hours. Just over 61 percent prefer between 20 and 35 hours per week and over 32 percent prefer full-time work. In contrast, just under half of the retired have no desire to work. Those that do overwhelmingly prefer part-time work, with 16 percent preferring fewer than 20 hours per week and 32 percent preferring 20 to 35 hours per week. There is a bit more dispersion among the others classified as out of the labor force. About one-third prefer not to work; another 16 percent prefer to work less than 20 hours; 37 percent prefer part-time work between 20 and 35 hours; and 12 percent prefer a full-time job.

There is also considerable heterogeneity by demographic groups. Table 4 reports mean adjusted hours gaps by gender, age, and education for all individuals and individuals grouped by broad labor force category-full-time employed, part-time employed, unemployed or out of the labor force and wanting work, and others out of the labor force. We group those that want work with the unemployed since they exhibit similar behavior in terms of their desired hours and reservation wages. We also report the mean desired hours for each demographic group to illustrate the differences independent of hours worked. Men prefer to work about 3.4 more hours per week than women, but their estimated hours gap is only 1.2 hours per week smaller. The gender differences by labor force status suggest that the overall gender differences in the desired hours gap are driven predominantly by gender differences in labor force status rather than by differences within labor force states. Younger and prime-aged workers have very similar desired work hours, though the hours gap for prime-aged workers is 3.4 hours smaller, on average. Differences within labor force states suggest that composition, for the most part, plays a dominant role in driving this result, though younger workers who are out of the labor force have a considerably larger hours gap than prime- 
aged workers who are out of the labor force. Older workers prefer much fewer hours than prime-aged workers, 20.3 hours per week compared to 33.0 hours per week. Their desired hours gap is 3.2 hours per week higher, but is driven primarily by composition. Within labor force states, older workers have the same or smaller hours gaps as prime-aged workers. Finally, desired hours rise with education. Those with a highschool degree or less prefer 25.0 hours of work per week, while those with at least a college degree prefer 30.0 hours of work per week. The college educated also have a smaller hours gap, on average. Their gap is about 4.2 hours per week, compared to about 6.4 hours per week for those with less than a college degree. Again, educational differences in labor force status appear to account for most of the hours gap variation, as the gaps within labor force states are roughly comparable. ${ }^{12}$

\subsection{Validating Desired Hours as a Measure of Potential Labor Supply}

A concern about self-reported desired hours may be that they represent "cheap talk," i.e., respondents may report an ideal work situation but their employment and job search behavior reflect something entirely different. If this were the case, it would call into question the use of self-reported desired hours for our measure of labor market underutilization. To address this potential issue, we perform a validation exercise to examine the relationship between search effort and the desired hours gap reported in the data. If desired work hours truly reflect slack, then individuals with a gap between their actual and desired work hours should be looking for better work. Presumably, those with larger hours gaps should exert greater effort. Since job search is costly in terms of time and effort it provides a useful benchmark for evaluating whether reported desired hours reflect one's desired labor supply.

Table 5 shows that there is a clear link between the reported desired hours gap and reported search effort. The table reports coefficient estimates from regressions of measures of search effort on the desired hours gap across our pooled sample of respondents in the SCE Job Search supplement. We estimate the

\footnotetext{
${ }^{12}$ We report additional results by race and marital status in the appendix. Married individuals tend to prefer more work hours than single individuals, and the desired hours gap of married individuals is somewhat smaller. Black and Hispanic individuals tend to prefer more work hours than white individuals, and their desired hours gaps are larger as well, which is consistent with these groups experiencing higher unemployment rates. The hours gap among blacks is particularly large compared to the other racial groups.
} 
relationship pooling all individuals together and using separate categories for each broad labor force state (employed, unemployed, or out of the labor force) and a separate indicator for whether the hours gap is nonnegative or negative. To test robustness, we also run regressions where we control for survey year and the demographics used in our estimation of the Aggregate Hours Gap (age, sex, education) as well as additional demographics (race, marital status, number of household children). We also use two measures of search effort. The top panel of Table 5 reports results using a dummy variable equal to one if the individual actively searched in the prior four weeks and the bottom panel of Table 5 reports results using the inverse hyperbolic sine of the number of applications sent within the last four weeks. ${ }^{13}$ Across all regression specifications, there emerges a statistically significant and positive relationship between our measures of search effort and the desired hours gap, with two notable caveats. First, search effort and the hours gap are essentially unrelated for the unemployed, but as the evidence in the previous subsection suggests, this is because most unemployed prefer full time work and nearly all search very intensely relative to the other groups. Thus, there is little variation in either variable for the unemployed. Second, among the employed, those with negative gaps exert higher search effort as well. In fact, the point estimates are notably larger in magnitude than the estimates for those with positive hours gaps. The estimates suggest a U-shaped relationship between search effort and the hours gap for the employed, a pattern we confirm with a graphical analysis of the data in the appendix. The evidence from Figure 1 shows that these individuals are disproportionately multiple jobholders, suggesting that their additional job(s) reflect slack in some way (see Shishko and Rostker, 1976). The positive relationship between negative hours gaps and search effort is also consistent with the findings of Bell and Blanchflower (2018a), who find that employed individuals with both positive and negative desired hours gaps have lower reported levels of well-being. While interesting in its own right, we leave the notion of slack among those with negative hours gaps for future research.

\footnotetext{
${ }^{13}$ The inverse hyperbolic sine is a close approximation to the natural $\log$ of applications sent, but allows for the inclusion of zero applications in its measurement. We also replicated the analysis for the inverse hyperbolic sine of hours spent searching for work and get nearly identical results to those reported in Table 5.
} 
Overall, we consider our validation exercise in Table 5 as strong evidence that desired hours reported in our SCE Job Search supplement are a reliable measure of potential labor supply.

\section{A Comprehensive Measure of Labor Market Underutilization}

We now turn to the estimation and time-series behavior of the Aggregate Hours Gap (AHG). Our measure is based on the gap between desired and actual work hours observed in the data. We use our measure of desired hours estimated from the SCE Job Search supplement and combine it with the reported work hours and monthly population shares that we estimate from the CPS. In this section, we describe our methodology for creating the AHG measure, including our estimate of its time trend, and examine its timeseries behavior over our sample period.

\subsection{Deriving the Aggregate Hours Gap}

Recall from Section 2 that one can define a typical measure of labor market underutilization as the ratio of some gap to a measure of potential labor supply. In this subsection, we derive our measure of labor market underutilization: the Aggregate Hours Gap. The AHG uses population share estimates for each of our nine detailed labor force states and weights them using a measure of the average desired hours gap within each category. Our desired hours gap measure is the difference between desired work hours and actual work hours. Define the share of the population in labor force state $j$ in month $t$ as $\omega_{j t}$, with $\sum_{j} \omega_{j t}=$ 1. Our measure of the gap is the sum of these population shares in each state $j$ weighted by its average desired hours gap, $L_{j t}-h_{j t}$. Similarly, our measure of potential labor supply is the sum of these population shares weighted by their desired hours alone, $L_{j t}$.

In practice, we have limited time-series variation in the SCE Job Search supplement, which is our only data source for desired hours. This forces us to use a measure of desired hours that is time-invariant within our defined labor force groups. We generate an average of desired hours for respondents pooled across all years for each labor force state interacted with an unbalanced set of $d$ demographic groups. Disaggregating the data further by demographic groups allows for time-variation in potential labor supply 
through changes in the demographic composition of each labor force state over time. ${ }^{14}$ The demographic groups we use are gender, three age groups (18-24, 25-54, and 55+ years old), and two education groups (less than a college degree, and college degree or more). The grouping is unbalanced because we do not have enough data within every labor force state to split each one into the 12 resulting demographic groups. We instead group individuals in each state based on the similarity of their mean desired hours and the sparsity of their sample cells in the SCE data. This results in a total of 39 labor force status $\times$ demographics estimates of desired hours, $L_{d j}$, out of a possible 108 estimates. ${ }^{15}$ All labor force states are at least disaggregated by gender, and larger categories are disaggregated further by age group and education as the data allow. The most disaggregated category is the full-time employed with a single job (10 out of 12 demographic categories), and the least disaggregated categories are the part-time employed with multiple jobs, the short-term and long-term unemployed, and those who are out of the labor force but want work (each only disaggregated by gender). ${ }^{16}$

Specifically, let $\tilde{L}_{d j}$ be the (unadjusted) mean desired hours calculated for each of the 39 demographics $\times$ labor force status categories from the SCE Job Search supplement. Let $h_{i j t}$ be the total usual work hours across all jobs for individual $i$ measured from the CPS. We use the imputation methodology in Mueller (2017) to adjust the usual hours of the main job for respondents who reply that their weekly hours vary. We merge the $\tilde{L}_{d j}$ estimates to the CPS micro data for respondents in each month between 1994 and 2018. We then adjust the desired hours at the individual level to impose the constraint

\footnotetext{
${ }^{14}$ Mueller (2017) shows that there are significant cyclical changes in the composition of the unemployed in terms of prior wages and demographics.

${ }^{15}$ In the appendix, we report the mean desired hours and the adjusted hours gaps from the SCE data for our 39 groups, and provide more detail on how we decide the aggregation across groups.

${ }^{16}$ In the appendix, we report the results of an exercise where we estimate time-varying measures of desired hours. We generate these estimates as out-of-sample-predictions using the estimated relationship between reported desired hours and a set of covariates that includes the state-level unemployment rate gap, average part-time and full-time hours worked, and the work hours of the individual respondent. We estimate this relationship using the SCE data and interact the coefficients with the state-level labor market data and the micro data in the CPS to generate a predicted desired hours estimate for each individual. Unfortunately, the small sample size, short time series, and annual nature of the SCE data do not provide enough time-series variation to give our estimation exercise much predictive power. Consequently, we use the time-invariant measures as our preferred measure of desired hours.
} 
of a zero minimum hours gap as we did for the estimates of the desired hours gap reported in Table 3. Specifically, adjusted desired hours are

- $\quad L_{d(i) j}=\tilde{L}_{d j} \quad$ for all non-employed, and

- $\quad L_{d(i) j}=\max \left\{\tilde{L}_{d j}, h_{i j t}\right\} \quad$ for all employed.

We topcode our individual-level measures of desired hours in the SCE and total usual hours in the CPS at 80 hours per week to avoid adverse effects of any outliers. The desired hours gap for each individual in the CPS in month $t$ is $L_{d(i) j}-h_{i j t}$. We aggregate these gaps within each labor force state as

$$
L_{j t}-h_{j t}=\sum_{i \in j} \frac{\omega_{i j t}}{\omega_{j t}}\left(L_{d(i) j}-h_{i j t}\right) .
$$

That is, the mean desired hours gap for labor force state $j$ in month $t$ is the population-weighted mean calculated across all individuals in $j$, where $\omega_{i j t}$ is the share of the population made up by individual $i$ (i.e., the sample weight) and $\omega_{j t}$ is the share of the population in labor force state $j$ in month $t$. Both are calculated using the monthly CPS data. Note that our measure of the gap within labor force state $j$ will vary over time due to changes in the demographic composition of those in state $j$, and among the employed, changes in hours worked. Our measure of potential labor supply is similarly calculated as

$$
L_{j t}=\sum_{i \in j} \frac{\omega_{i j t}}{\omega_{j t}} L_{d(i) j}
$$

Our measure of potential labor supply within labor force state $j$ will also vary over time due to changes in the demographic composition of those in state $j$. Plugging our measures for the desired hours gap and potential labor supply into equation (1) implies that the AHG measure is

$$
S_{t}=\frac{\sum_{j} \omega_{j t}\left(L_{j t}-h_{j t}\right)}{\sum_{j} \omega_{j t} L_{j t}} .
$$

The numerator of equation (3), the gap, will vary over time due to the demographic and work hours variation noted above, as well as variations in the population share of each labor force state $j$. The denominator of equation (3), potential labor supply, will vary over time due to the demographic changes noted above and changes in the population share of each labor force state $j$. 


\subsection{Labor Market Underutilization over the Business Cycle}

We can estimate equation (3) in parts, aggregating up to our measure of underutilization in a variety of ways. We focus on the AHG measure, $S_{t}$, and its separate contributions by detailed labor force states.

Figure 2 shows the time-series behavior of the AHG measure and the behavior of its contributions from the employed, unemployed, and those out of the labor force. Note that the contributions all use total potential labor supply in their denominator so that they sum to $S_{t}$. Overall, the AHG measure suggests that the desired hours gap averages about 19.9 percent of potential labor supply over our sample period. It is strongly countercyclical, though it tends to peak following the end of each recession in our sample, reaching a peak of 19.8 percent in mid-2003 and a peak of 23.8 percent in mid-2010. The measure is at its lowest, at 17.3 percent, in early 2000 . The contribution of the unemployed to the AHG measure behaves very similarly to the official unemployment rate. It is also similar to the unemployment rate in magnitude, despite differing measures in their numerators and denominators. There are small cyclical variations in the contribution of the employed to overall labor market underutilization, but the contribution of the employed in any given month is relatively small (about 2 percentage points, on average), so the cyclical variation contributes little to movements in the population-wide AHG measure. Changes in the contribution of those out of the labor force, however, have a considerable effect on the AHG measure. Over the entire sample period, their contribution varies from a low of 12.5 percent during the late 1990 s to a peak of 15.0 percent in late 2015 . The cyclicality of their contribution also differs considerably, particularly during the three expansion periods in our sample. During the two recession periods, the contribution of those out of the labor force to the AHG measure rises considerably and continues to rise following the end of the recession. During the 1990s expansion, their contribution falls continuously until the start of the 2001 recession. Following the 2001 recession, their contribution continues to rise following the recession, remains elevated until early 2005, with only a modest decline thereafter. Following the Great Recession, their contribution continues to rise for years. After reaching its peak in 2015, it finally starts to decline, but is still at 14.2 percent at the end of 2018. This elevated level of underutilization among those out of the labor force offsets the large 
decline of the unemployment contribution over the same period and leads to the relatively sluggish decline in the AHG measure following the Great Recession.

Figure 3 reports the time-series behavior by our more detailed labor force states. We again report them as a fraction of total potential labor supply so that they sum to be equal to the population-wide AHG measure. The top panel of Figure 3 shows that the contribution of the unemployed to the rise in underutilization during each recession is initially driven by the short-term unemployed but is eventually driven primarily by the long-term unemployed. The decline in the underutilization among the long-term unemployed is particularly sluggish following the Great Recession. The top panel also shows differing behavior for the contributions of those out of the labor force that depends on whether individuals want work, are retired, or are out of the labor force for other reasons. Those that want work or are out of the labor force for other reasons exhibit a countercyclical contribution to the AHG measure, and those who are out of the labor force for other reasons have the largest contribution to the AHG measure. Following both recessions, however, the contributions of those who want work or are out of the labor force for other reasons remain elevated for some time. By the end of 2018, the contribution of those who want work is roughly back at its pre-recession level of 1.5 percent, but the contribution of those out of the labor force for other reasons remains somewhat elevated, at 7.4 percent, compared to its pre-recession level of 7.0 percent. The contribution of the retired is relatively large but acyclical. Up until 2012, their contribution is essentially constant, averaging about 4.3 percent of potential labor supply. It rises steadily thereafter, however, and stands at 5.2 percent at the end of 2018. The bottom panel of Figure 3 breaks out the contribution of the employed by detailed category. It shows that nearly the entire contribution, as well as its (countercyclicality, is driven by part-time, single jobholders.

The contributions of these different labor market states lead our AHG measure to paint a picture of labor market slack that is similar to what is implied by the standard measures of underutilization prior to the Great Recession, but quite different thereafter. Figure 4 reports the official U3 measure of the unemployment rate for our sample and our AHG measure. We shift the axis of the latter for better comparison to the unemployment rate. Throughout the 1990s and during the 2001 recession, the AHG 
measure tracks the unemployment rate very closely. Following the Great Recession, however, the AHG measure is much more sluggish in its decline than the unemployment rate. The unemployment rate peaks in the second quarter of 2010 and begins a steady decline thereafter. In contrast, our measure remains elevated until the middle of 2011 and its decline thereafter is more sluggish in both relative and absolute terms. By the end of 2018, the unemployment rate has fallen 6.1 percentage points to about 3.7 percent, while the AHG measure has only fallen 4.8 percentage points to 18.9 percent. ${ }^{17}$

Figure 5 shows that the AHG measure captures a different, and greater, degree of slack following the Great Recession than broader measures of underutilization that are currently available. In Figure 5, we plot the difference over time between the BLS U6 and U3 measures of unemployment. The former additionally includes those who report working part-time for economic reasons and who are identified as marginally attached to the labor force. We also plot the difference over time between the AHG measure and the U3 unemployment rate. The differences between the U6 and U3 measures are strongly countercyclical and suggest a greater degree of labor market slack during and after the Great Recession than the U3 measure alone. The difference, however, nearly returns to its pre-recession level by 2018 . The difference between the AHG measure and the U3 measure is somewhat countercyclical, but rises with a much longer lag than the U6-U3 difference. Moreover, the difference between the U3 rate and our measure continues to rise following the Great Recession even as the U6-U3 difference begins to narrow. By the end of 2018, the AHG-U3 difference remains 2.5 percentage points higher than it was prior to the start of the Great Recession. Again, the AHG measure suggests a larger and more persistent degree of underutilization in the labor market following the Great Recession.

Finally, Figure 6 shows that, despite the differences between the AHG measure and the unemployment rate, our measure of potential labor supply - i.e., the average desired work hours across the population - tracks the labor force participation rate closely. This is especially true during the 1990s and

\footnotetext{
${ }^{17}$ In the appendix, we show that the difference is notably smaller when we restrict our sample to prime-aged men (age 25-54). Their unemployment rate falls by 5.9 percent, while their measure of underutilization falls by 5.6 percent over the same period.
} 
since 2013. Between 2000 and 2005, potential labor supply falls somewhat more than the labor force participation rate. It remains lower, though the participation rate begins to close the gap between the two starting in 2010 and continues to do so until the two measures begin to track each other closely again in 2013.

\subsection{Trend versus Cyclical Movements in the Aggregate Hours Gap}

The Aggregate Hours Gap measure shows a relatively high degree of labor market underutilization following the Great Recession, but it is not clear how much of that is due to demographic factors. Demographic changes, notably the retirement of the baby boomer generation, likely play a role in driving the rise in the AHG measure, as Figure 3 shows. One way to assess the importance of demographic factors is to compute the AHG for different demographic groups, and then multiply the value by their share in the population. In doing so, we find that the contribution of older individuals to our slack measure is relatively acyclical but has been rising steadily since the Great Recession. We also find increases in the contribution of the college educated (driven primarily by a rise in the population's college share) and we find that cyclicality is concentrated among men and those with less than a college degree. Consequently, demographics are a key contributor to movements in the AHG measure. ${ }^{18}$

To estimate the contribution of demographic changes to the AHG measure more systematically, we develop an estimate of its trend movements that are due to demographic changes in labor force states. In doing so, we draw from the methodology of Aaronson et al. (2014), who use a mix of demographic and cyclical factors to develop a trend estimate for the labor force participation rate. We use their approach to estimate trend movements in the population shares of each labor force state $j$. Using a logit specification, we estimate the log odds ratio of the probability that an individual is in labor force state $j$ during month $t$ as a function of observable demographic and business cycle characteristics. We do this separately for eight

\footnotetext{
${ }^{18}$ We report the results of this exercise in the appendix.
} 
of our nine states, since the ninth trend estimate is just equal to one minus the sum of the other eight trend estimates. Our specification is

$$
\omega_{i j t}=\mu_{g e a j}+\rho_{g e d j} \hat{u}_{s t}+\delta_{g e j, \tau}+\zeta_{g e r j}+\lambda_{g e j} Z_{m c(i)}+\sigma_{g e j t}+\eta_{i g e j t}
$$

where $\omega_{i j t}$ is an indicator equal to one if individual $i$ is in labor market state $j$ at time $t$ and $\mu_{\text {sea } j}$ is a set of fixed effects for gender $g$, education group $e$, and age group $a$. We group individuals into one of two education categories (less than a college degree or at least a college degree) and into 5-year age intervals. Our measure of cyclical variations is $\hat{u}_{s t}$, which is the unemployment rate gap in state in $s$ at month $t$. We measure the unemployment rate gap as the quarterly mean of the difference between the state unemployment rate and the CBO estimate of the short-run NAIRU, after conditioning out state fixed effects, and use the 4-quarter moving average of this quarterly mean. We also include a set of birth cohort fixed effects, $\delta_{g e j, \tau}$, that group individuals by gender, education, and 8-year intervals of their birth year. The $\zeta_{\text {ger } j}$ term represents a set of race fixed effects (white, black, Hispanic, or other) that vary by gender and education. For individuals aged 25-54, we include a set of dummy variables, $Z_{m c(i)}$, equal to one if the individual is married with any young household children (under six years old), single with any young household children, or married with no young children (with singles with no children being the excluded category). Finally, $\sigma_{\text {gejt }}$ represents a set of quarter-of-year dummies that vary by gender and education and $\eta_{\text {igejt }}$ is the error term.

We estimate (4) using the CPS micro data over our full 1994-2018 sample period, and due to computational constraints, estimate the model separately by gender and education group within each labor market state. Our estimate of the trend for each population share in labor market state $j$ is the weighted average of the predicted probability from (4) less the contribution predicted by the state unemployment rate gap, $\hat{u}_{s t}$. That is, $\omega_{j t}^{*}=\sum_{i} \widehat{\omega}_{i j t}$, where $\widehat{\omega}_{i j t}$ are the predicted values less the contribution of $\hat{\rho}_{\text {ged }} \hat{u}_{s t}$.

We then generate estimates of trend potential labor supply and the trend of the AHG measure. Given the definition of our measure in (3), our measure of trend potential labor supply is 


$$
L_{t}^{*}=\sum_{j} \omega_{j t}^{*} L_{j t}
$$

and our measure of the AHG trend is

$$
S_{t}^{*}=\frac{\sum_{j} \omega_{j t}^{*}\left(L_{j t}-h_{j t}\right)}{\sum_{j} \omega_{j t}^{*} L_{j t}} .
$$

Figure 7 reports the estimated demographic trend of the AHG measure along with its actual estimates. The trend estimate is roughly constant between 1994 and 2007, averaging about 19.3 percent of potential labor supply over this time. The trend rises steadily starting 2007, however, to about 21.4 percent by the end of 2018. Despite this rising trend, our estimates suggest that the AHG measure was well above its trend during and after the Great Recession, and that it did not fall below trend until the beginning of 2016. Figure 8 shows the actual and trend estimates of potential labor supply. The two measures track each other closely. Potential labor supply is above its trend between 1996 and 2000, and again between 2006 and 2007. It remains well below its trend between 2009 and 2016, but then rises above trend and remains above trend through 2018. Notably, the differences between the trend and actual labor force participation rates estimated by Aaronson et al. (2014) follow a similar pattern.

\section{Implications of Labor Market Underutilization for Wage Pressures}

We conclude our analyses with evaluations of how the Aggregate Hours Gap measure relates to wage growth. We begin by estimating the relationship between nominal wage growth and various measures of labor market underutilization at the national level. We then move on to a state-level analysis. First, we examine the differences in the behavior of our measure and the standard U3 unemployment rate at the state level during and after the Great Recession. We then use the within-state time-series behavior of both measures to see how they compare in predicting nominal wage growth over our sample period. 


\subsection{National-level Relationships between Wages and Labor Market Underutilization}

We start with estimating the national-level relationship between nominal wage growth and various measures of underutilization. We use the year-over-year change in the (log) median nominal wage, estimated for all individuals aged 18 to 79 , as our measure of nominal wage growth. We obtain the wage data from the Outgoing Rotation Group panel of the CPS. We estimate the regressions at the quarterly frequency, so use the quarterly average of monthly wage changes, which we further smooth using a fourquarter moving average of the quarterly estimates. The smoothing is necessary given the noisy nature of the smaller cell sizes of the state-level CPS data. We regress this wage measure on several measures of underutilization. These include: (i) the unemployment rate; (ii) the unemployment rate gap (measured as the difference between the unemployment rate and the short-run NAIRU produced by the Congressional Budget Office); (iii) the unemployment rate broken out by short-term (0-5 weeks), medium-term (6-26 weeks), or long-term ( 27 or more weeks) unemployed, along with the quarterly quit rate estimated by Davis, Faberman, and Haltiwanger (2012), which we extend through 2018; (iv) the Nonemployment Index (including those part-time for economic reasons) developed by Hornstein, Kudlyak, and Lange (2014); (v) the AHG measure; (vi) the AHG measure relative to its demographic trend; and (vii ) the AHG measure broken out by its contributions from the employed, unemployed, and those out of the labor force. We use a four-quarter moving average of each of these measures, and estimate each specification using maximum likelihood over the 1995-2018 period, allowing for an autoregressive error structure with a three-quarter lag.

Our results are reported in Table 6. Nearly all estimates of underutilization are significantly negatively related to nominal wage growth, so we focus on the performance of each measure in accounting for the variation in wage growth based on their regression adjusted R-squared values and their reduction in the regression root mean squared errors (RMSE). The unemployment rate and unemployment rate gap measures account for a similar amount of the variation in wage growth, with adjusted R-squared values of about 0.12 and an RMSE of 0.424 and 0.425 , respectively. The specification with the unemployment rate 
broken out by duration and with the quit rate added performs somewhat worse, with an R-squared value of 0.08 and an RMSE of 0.427. The Nonemployment Index of Hornstein, Kudlyak, and Lange (2014) performs considerably better, with an R-squared of 0.19 and a RMSE of 0.421 , as does the AHG measure. The AHG measure has an R-squared of 0.17 and an RMSE of 0.421 for its actual estimate as well as its estimate relative to its demographic trend. Our measure does not perform better than the NEI, but keep in mind that the NEI uses ex post realizations of transitions across labor force states, while our measure uses ex ante elicitations of desired hours. Moreover, our measure performs even better when we disaggregate it by its contributions from the employed, unemployed, and those out of the labor force, with an adjusted R-squared of 0.24 and an RMSE of $0.419 .{ }^{19}$ As a final note, we would emphasize that an advantage of the AHG over other measures of slack is that it is a comprehensive measure that has a direct correspondence to inputs used in potential output calculations.

\subsection{State-level Relationships between Wages and Labor Market Underutilization}

Next, we examine whether the AHG measure paints a different picture relative to the standard unemployment rate over time within U.S. states. We start by computing both measures at the state level and averaging their values over the 2007-11 and 2012-18 periods. We then compare their cross-sectional relationships across the two time periods. Figure 9 reports our results. We find that the across-state relationship between the AHG measure and the unemployment rate shifted considerably following the Great Recession. The figure shows that most states experienced only a modest decline in their estimates of the AHG measure despite substantial declines in their unemployment rate. Consequently, the relationship between our measure and the unemployment rate exhibits a considerable leftward shift in the figure. In several cases, such as for West Virginia, our measure of underutilization rose while the unemployment rate fell.

\footnotetext{
${ }^{19}$ In a separate set of results, we also found that the AHG effect remains negative and increases predictive power when added in parallel to the other measures of underutilization in Table 6 and 7.
} 
We also replicate our wage growth regressions at the state level, exploiting within-state, time-series variation in nominal wages and measures of labor market underutilization. Arguably, the variation captures the cyclical relationship between these two measures, since it is able to control for state-specific and aggregate factors that can confound the estimation. Our approach is similar to those taken by Dent et al. (2014), Kiley (2015), and Aaronson and Jordan (2014), who exploit within-state, time-series variation to examine how the composition of unemployment by duration affects wages.

We replicate the national-level wage analysis using fixed effects regressions at the quarterly frequency, where we include fixed effects for states and time. We again regress the four-quarter moving average of the growth of nominal median wages on the two measures of labor market underutilization. ${ }^{20}$ Our underutilization measures are the four-quarter moving averages of: (i) the state-level unemployment rate from the Local Area Unemployment Statistics of the BLS, (ii) the AHG measure computed for each state, and (iii) the contributions of the employed, unemployed, and those out of the labor force to our underutilization measure. ${ }^{21}$ We estimate each specification using a fixed effects regression (with and without time fixed effects included) and cluster the standard errors by state and quarter.

Our results are displayed in Table 7. When we include both state and time fixed effects, we find that both measures exhibit a significant negative relationship to nominal wage growth within states over time. The time fixed effects absorb cyclical movements in wages and labor market underutilization that are common across all states, and therefore may mask how well each measure captures the time-series behavior of wage growth. Consequently, we replicate our analysis excluding the time fixed effects and find that both measures have even stronger negative relations to nominal wage growth within states. Furthermore, all three of our measure's components exert significant negative wage pressures on the state-level nominal wages, with underutilization among the employed exhibiting the strongest downward wage pressures.

\footnotetext{
${ }^{20}$ Since some months have relatively small samples at the state level, we use a weighted average rather than a simple average quarterly wage growth, where we weight each month by the minimum number of observations in its current or 12-month lagged wage estimate.

${ }^{21}$ We ignore the gap measure and measures relative to trend since the underlying NAIRU and trend are measured at the national level and are therefore captured by the time fixed effects.
} 
Though far from definitive, the evidence is consistent with the findings of Faberman and Justiniano (2015), Karahan et al. (2017), and the job-ladder models of Faccini and Melosi (2019) and Moscarini and PostelVinay $(2016,2019)$, among others, which highlight the role of job-to-job transitions for wage dynamics. The significantly negative relationship between the contribution from those out of the labor force and wage growth is also consistent with recent evidence by Barnichon and Figura (2015), Ameriks et al. (2020), and Abraham et al. (2020), which highlights the importance of employment transitions by retired workers and other labor force non-participants.

\section{Conclusions}

In this paper, we develop the Aggregate Hours Gap, a comprehensive measure of labor market underutilization that exploits multiple data sources. Our measure is based on the notion that one's desired work hours reflect their potential labor supply, and any gap between their desired hours and actual work hours reflects some degree of labor market slack. Consequently, our measure does not rely on a particular definition of the labor force and does not count individuals equally, instead weighting them by their desired and actual work hours. This notion of labor market underutilization connects more directly to the estimation of potential output since it provides a comprehensive hours-based measure of labor market slack. Our measure of desired hours comes from a survey on job search we developed in earlier work (Faberman et al., 2017). We estimate desired hours for a variety of demographic groups and detailed labor force states and find considerable variation across all groups. We also find that there are notable transitions of individuals across detailed labor market states even within broader labor force categories (i.e., employment unemployment, and out of the labor force).

We find that there are substantial deviations between the AHG measure and the unemployment rate following the Great Recession. Prior to the Great Recession, however, the two measures tracked each other closely. The AHG measure also captures differential movements in labor market slack than other alternative measures, such as the BLS "U6" measure of underutilization. Finally, we show that these deviations have a meaningful impact on wages. At both the national and state level, the AHG measure is strongly negatively 
related to nominal wage growth, and performs at least as well as the unemployment rate in predicting wage movements. When broken out into its component parts, our measure suggests a significant role for the employed and those out of the labor force, in addition to the unemployed, in predicting wage movements. Thus, our measure provides a useful characterization of the relationship between labor market slack and wage fluctuations.

For these reasons, we believe it would be valuable to include questions about desired hours in government labor force surveys, as is done with the U.K. Labor Force Survey. Due to the limited time series coverage of the SCE job search supplement, an important caveat of our analysis is that we use a timeinvariant measure of desired hours in our slack measure. A longer time series of desired work hours would provide insight on their cyclicality. Another important caveat is that we do not account for overemployment, which occurs when individuals desire to work fewer hours than they currently do. Our validation exercise, as well as recent research, suggests that overemployment likely represents an additional degree of slack. We leave these important tasks for future research, as more data become available. 


\section{References}

Aaronson, Daniel, Luojia Hu, Arian Seifoddini, and Daniel G. Sullivan, 2014. "Declining labor force participation and its implications for unemployment and employment growth." Economic Perspectives 38(4).

Aaronson, Daniel, and Andrew Jordan. "Understanding the relationship between real wage growth and labor market conditions." Chicago Fed Letter No. 327 (2014).

Abraham, Katherine G., and John C. Haltiwanger, 2019. "How Tight is the Labor Market?" mimeo.

Abraham, Katharine G., Brad Hershbein, and Susan Houseman, 2020. "Contract Work at Older Ages." NBER Working Paper No. 26612.

Ameriks, John, Joseph Briggs, Andrew Caplin, Minjoon Lee, Matthew D. Shapiro, and Christopher, 2020. "Older Americans would Work Longer if Jobs were Flexible." American Economic Journal: Macroeconomics, 12(1), 174-209.

Barnichon, Regis, and Andrew Figura, 2015. "Declining Desire to Work and Downward Trends in Unemployment and Participation.” NBER Macroeconomics Annual, 30(2015), 449-494.

Bell, David NF, and David G. Blanchflower. "Underemployment in the UK in the Great Recession." National Institute Economic Review 215, no. 1 (2011): R23-R33.

Bell, David NF, and David G. Blanchflower, 2013. "Underemployment in the UK Revisited." National Institute Economic Review 224(1): F8-F22.

Bell, David NF, and David G. Blanchflower, 2018a. "The Well-Being of the Overemployed and the Underemployed and the Rise in Depression in the UK." National Bureau of Economic Research No. w24840.

Bell, David NF, and David G. Blanchflower, 2018b. "Underemployment in the US and Europe." No. w24927. National Bureau of Economic Research.

Crump, Richard K., Stefano Eusepi, Marc Giannoni, and Ayşegül Şahin, 2019. "A Unified Approach to Measuring $u$ *.” No. w25930. National Bureau of Economic Research.

Dent Rob, Sam Kapon, Fatih Karahan, Ben Pugsley and Ayşegül Şahin. "The Long-term Unemployed and Wages of New Hires.” Liberty St Blog, November 2014.

Eekhout, Jan, and Ilse Lindenlaub. 2019. "Unemployment Cycles." American Economic Journals: Macroeconomics,11(4), 175-234.

Elsby, Michael W. L., Bart Hobijn, and Ayşegül Şahin, 2015. "On the Importance of the Participation Margin for Labor Market Fluctuations.” Journal of Monetary Economics, 72(1): 64-82.

Faberman, R. Jason, and Alejandro Justiniano, 2015. "Job Switching and Wage Growth." Chicago Fed Letter No. 337.

Faberman, R. Jason, and Marianna Kudlyak. 2019. "The Intensity of Job Search and Search Duration." American Economic Journals: Macroeconomics, 11(3), 327-357. 
Faberman, R. Jason, Andreas I. Mueller, Ayşegül Şahin and Giorgio Topa, 2017. "Job Search Behavior among the Employed and Non-Employed,” NBER Working Paper No. 23731.

Faccini, Renato, and Leonardo Melosi, 2019. "Bad Jobs and Low Inflation.” CEPR Discussion Paper No. DP13628.

Hall, Robert E., and Sam Schulhofer-Wohl, 2018. "Measuring Job-Finding Rates and Matching Efficiency with Heterogeneous Job-Seekers." American Economic Journal: Macroeconomics 10(1): 1-32.

Hall, Robert E., and Andreas I. Mueller, 2018. "Wage Dispersion and Search Behavior: The Importance of Non-Wage Job Values.” Journal of Political Economy 126(4): 1594-1637.

Hornstein, Andreas, Marianna Kudlyak, and Fabian Lange, 2014. "Measuring Resource Utilization in the Labor Market." FRB Economic Quarterly 100(1): 1-21.

Kiley, Michael T., 2015. "An evaluation of the inflationary pressure associated with short-and long-term unemployment." Economics Letters 137: 5-9.

Karahan, Fatih, Ryan Michaels, Benjamin Pugsley, Ayşegül Şahin, and Rachel Schuh, 2017. "Do Job-toJob Transitions Drive Wage Fluctuations over the Business Cycle?" American Economic Review 107(5): 353-57.

Krueger, Alan B., Judd Cramer, and David Cho. 2014. "Are the Long-Term Unemployed on the Margins of the Labor Market?" Brookings Papers on Economic Activity 1: 229-280.

Kudlyak, Marianna, and Fabian Lange. 2017. "Measuring Heterogeneity in Job Finding Rates Among the Nonemployed Using Labor Force Status Histories.” Federal Reserve Bank of San

Francisco Working Paper No. 2017-20.

Moscarini, Giuseppe, and Fabien Postel-Vinay. 2016. "Wage Posting and Business Cycles." American Economic Review 106 (5): 208-13.

Moscarini, Giuseppe, and Fabien Postel-Vinay. 2019. "The Job Ladder: Inflation vs. Reallocation.” Yale University, working paper.

Mueller, Andreas I., 2017. "Separations, Sorting and Cyclical Unemployment," American Economic Review 107(7): 2081-2107.

Mukoyama, Toshihiko, Christina Patterson and Ayşegül Şahin, 2018. "Job Search Behavior over the Business Cycle.” American Economic Journal: Macroeconomics 10(1) 190-215.

Shackleton, Robert, 2018. "Estimating and Projecting Potential Output using CBO's Forecasting Growth Model," CBO Working Paper Series, 2018-03.

Shimer, Robert. 2004. “Search Intensity.” University of Chicago, mimeo. 
Table 1. Population Shares and Monthly Transition Rates by Detailed Labor Force Status

\begin{tabular}{|c|c|c|c|c|c|c|c|c|c|c|c|}
\hline \multirow[b]{2}{*}{$\begin{array}{l}\text { Prior Month's } \\
\text { LFS }\end{array}$} & \multirow[b]{2}{*}{$\begin{array}{l}\text { Pop. } \\
\text { Share }\end{array}$} & \multirow[b]{2}{*}{$\begin{array}{c}\text { JF } \\
\text { Rate }\end{array}$} & \multicolumn{9}{|c|}{ Current Month's LFS } \\
\hline & & & $E^{f s}$ & $E^{f m}$ & $E^{p s}$ & $E^{p m}$ & $U^{s t}$ & $U^{l t}$ & $N^{w w}$ & $N^{r}$ & $N^{o}$ \\
\hline $\begin{array}{l}\text { Employed FT, } \\
\text { single job }\end{array}$ & .502 & .020 & .928 & .012 & .032 & .000 & .010 & .001 & .004 & .003 & .010 \\
\hline $\begin{array}{l}\text { Employed FT, } \\
\text { multi job }\end{array}$ & .031 & .040 & .281 & 644 & .041 & .021 & .004 & .001 & .002 & .001 & .005 \\
\hline $\begin{array}{l}\text { Employed, PT, } \\
\text { single job }\end{array}$ & .101 & .034 & .170 & .011 & .710 & .010 & .022 & .002 & .011 & .020 & .042 \\
\hline $\begin{array}{l}\text { Employed PT, } \\
\text { multiple job }\end{array}$ & .004 & .076 & .067 & .158 & .292 & .443 & .012 & .004 & .007 & .008 & .017 \\
\hline $\begin{array}{l}\text { Unemployed } \leq 6 \\
\text { months }\end{array}$ & .027 & .289 & .183 & .005 & .099 & .002 & .458 & .046 & .088 & .015 & .104 \\
\hline $\begin{array}{l}\text { Unemployed }>6 \\
\text { months }\end{array}$ & .010 & .147 & .086 & .004 & .054 & .002 & .017 & .580 & .119 & .023 & .118 \\
\hline $\begin{array}{l}\text { Not in LF, } \\
\text { want to work }\end{array}$ & .019 & .156 & .088 & .003 & .064 & .001 & .137 & .054 & .273 & .068 & .312 \\
\hline $\begin{array}{l}\text { Not in } L F, \\
\text { retired }\end{array}$ & .166 & .015 & .005 & .000 & .010 & .000 & .002 & .001 & .001 & .973 & .008 \\
\hline $\begin{array}{l}\text { Not in LF, } \\
\text { other }\end{array}$ & .141 & .059 & .031 & .001 & .027 & .000 & .017 & .005 & .035 & .025 & .859 \\
\hline
\end{tabular}

Note: Table reports monthly transition rates between the nine listed labor force states, as well as their share of the total population and their job-finding rate (i.e., transition into any new employment), pooled across all months between January 1994 and December 2018. Sample is all individuals aged 18 to 79 in the Current Population Survey. 


\begin{tabular}{|c|c|c|c|c|c|c|}
\hline \multirow[b]{2}{*}{$\begin{array}{l}\text { Current Month's } \\
\text { LFS }\end{array}$} & \multirow[b]{2}{*}{$\begin{array}{c}\text { Pct. } \\
\text { Actively } \\
\text { Searched } \\
\end{array}$} & \multirow{2}{*}{$\begin{array}{c}\text { Pct. No } \\
\text { Search, } \\
\text { Would Take } \\
\text { Offer }\end{array}$} & \multirow[b]{2}{*}{$\begin{array}{c}\text { Mean } \\
\text { Applications } \\
\text { Sent }\end{array}$} & \multirow{2}{*}{$\begin{array}{c}\text { Mean } \\
\text { Hours } \\
\text { Spent } \\
\text { Searching }\end{array}$} & \multicolumn{2}{|c|}{ Conditional on Active Search } \\
\hline & & & & & $\begin{array}{l}\text { Pct. Looking } \\
\text { for Addl. Job } \\
\text { Only } \\
\end{array}$ & $\begin{array}{c}\text { Pct. Looking } \\
\text { P-T Only }\end{array}$ \\
\hline \multirow{2}{*}{$\begin{array}{l}\text { Employed FT, } \\
\text { single job }\end{array}$} & 19.0 & 4.9 & 0.79 & 0.76 & 28.8 & 23.2 \\
\hline & $(0.7)$ & $(0.4)$ & $(0.07)$ & $(0.07)$ & $(1.8)$ & $(1.7)$ \\
\hline \multirow{2}{*}{$\begin{array}{l}\text { Employed FT, } \\
\text { multi job }\end{array}$} & 22.4 & 8.8 & 0.97 & 1.23 & 35.1 & 17.4 \\
\hline & $(1.6)$ & $(1.1)$ & $(0.13)$ & $(0.18)$ & $(4.0)$ & $(3.2)$ \\
\hline \multirow{2}{*}{$\begin{array}{l}\text { Employed, PT, } \\
\text { single job }\end{array}$} & 23.4 & 4.8 & 2.03 & 2.16 & 44.3 & 25.1 \\
\hline & (1.6) & $(0.8)$ & $(0.31)$ & $(0.28)$ & (4.4) & $(3.8)$ \\
\hline \multirow{2}{*}{$\begin{array}{l}\text { Employed PT, } \\
\text { multiple job }\end{array}$} & 31.8 & 4.7 & 1.92 & 2.55 & 66.5 & 21.1 \\
\hline & $(3.0)$ & $(1.4)$ & $(0.27)$ & $(0.36)$ & $(5.5)$ & $(4.8)$ \\
\hline \multirow{2}{*}{$\begin{array}{l}\text { Unemployed } \leq 6 \\
\text { months }\end{array}$} & 96.0 & 0.4 & 9.66 & 10.44 & & 12.9 \\
\hline & $(1.7)$ & $(0.5)$ & $(1.19)$ & $(0.89)$ & -- & $(3.1)$ \\
\hline \multirow{2}{*}{$\begin{array}{l}\text { Unemployed }>6 \\
\text { months }\end{array}$} & 100.0 & 0.0 & 8.81 & 11.47 & & 17.3 \\
\hline & $(0.0)$ & $(0.0)$ & $(1.50)$ & $(1.30)$ & - & $(4.4)$ \\
\hline \multirow{2}{*}{$\begin{array}{l}\text { Not in LF, } \\
\text { want to work }\end{array}$} & 18.0 & 35.6 & 0.80 & 1.51 & & 8.6 \\
\hline & $(5.4)$ & (6.7) & $(0.43)$ & $(0.48)$ & -- & (9.3) \\
\hline \multirow{2}{*}{$\begin{array}{l}\text { Not in } L F \text {, } \\
\text { retired }\end{array}$} & 5.5 & 2.8 & 0.13 & 0.15 & & 71.7 \\
\hline & (0.6) & (0.4) & $(0.03)$ & $(0.03)$ & & (5.3) \\
\hline \multirow{2}{*}{$\begin{array}{l}\text { Not in LF, } \\
\text { other }\end{array}$} & 11.2 & 4.1 & 0.67 & 0.66 & & 46.7 \\
\hline & (1.3) & $(0.8)$ & $(0.19)$ & $(0.17)$ & --- & (6.6) \\
\hline
\end{tabular}

Notes: Sample is all individuals in the SCE Job Search supplement aged 18-79 pooled across its 2013-2018 surveys. Mean applications sent are for the preceding four weeks and hours spent searching are for the preceding seven days. Standard errors are in parentheses.

Table 3. Actual Hours, Desired Hours, and Wages by Detailed Labor Force Status

\begin{tabular}{|c|c|c|c|c|c|c|}
\hline $\begin{array}{l}\text { Current Month's } \\
\text { LFS }\end{array}$ & $\begin{array}{l}\text { Desired } \\
\text { Hours }\end{array}$ & $\begin{array}{l}\text { Adjusted } \\
\text { Hours Gap }\end{array}$ & $\begin{array}{l}\text { Total Work } \\
\text { Hours }\end{array}$ & $\begin{array}{l}\text { Main Job } \\
\text { Hours }\end{array}$ & $\begin{array}{l}\text { Main Job } \\
\text { Wage }\end{array}$ & $\begin{array}{l}\text { Reservation } \\
\text { Wage }\end{array}$ \\
\hline $\begin{array}{l}\text { Employed FT, } \\
\text { single job }\end{array}$ & $\begin{array}{l}36.24 \\
(0.22)\end{array}$ & $\begin{array}{c}0.40 \\
(0.04)\end{array}$ & $\begin{array}{l}43.02 \\
(0.15)\end{array}$ & $\begin{array}{l}43.02 \\
(0.15)\end{array}$ & $\begin{array}{c}\$ 31.73 \\
(0.72)\end{array}$ & $\begin{array}{c}\$ 32.86 \\
(0.59)\end{array}$ \\
\hline $\begin{array}{l}\text { Employed FT, } \\
\text { multi job }\end{array}$ & $\begin{array}{l}37.36 \\
(0.60)\end{array}$ & $\begin{array}{c}0.10 \\
(0.03)\end{array}$ & $\begin{array}{l}52.68 \\
(0.43)\end{array}$ & $\begin{array}{l}41.43 \\
(0.34)\end{array}$ & $\begin{array}{l}25.38 \\
(0.65)\end{array}$ & $\begin{array}{l}29.16 \\
(1.05)\end{array}$ \\
\hline $\begin{array}{l}\text { Employed, PT, } \\
\text { single job }\end{array}$ & $\begin{array}{l}23.94 \\
(0.44)\end{array}$ & $\begin{array}{c}4.05 \\
(0.27)\end{array}$ & $\begin{array}{l}21.80 \\
(0.42)\end{array}$ & $\begin{array}{l}21.80 \\
(0.42)\end{array}$ & $\begin{array}{l}25.03 \\
(3.86)\end{array}$ & $\begin{array}{l}27.90 \\
(3.89)\end{array}$ \\
\hline $\begin{array}{l}\text { Employed PT, } \\
\text { multiple job }\end{array}$ & $\begin{array}{l}29.02 \\
(0.98)\end{array}$ & $\begin{array}{c}1.33 \\
(0.29)\end{array}$ & $\begin{array}{l}34.57 \\
(1.06)\end{array}$ & $\begin{array}{l}22.51 \\
(0.68)\end{array}$ & $\begin{array}{l}22.04 \\
(1.58)\end{array}$ & $\begin{array}{l}25.37 \\
(1.90)\end{array}$ \\
\hline $\begin{array}{l}\text { Unemployed } \leq 6 \\
\text { months }\end{array}$ & $\begin{array}{l}36.05 \\
(0.89)\end{array}$ & $\begin{array}{l}36.05 \\
(0.89)\end{array}$ & 0.00 & 0.00 & --- & $\begin{array}{l}18.28 \\
(1.04)\end{array}$ \\
\hline $\begin{array}{l}\text { Unemployed }>6 \\
\text { months }\end{array}$ & $\begin{array}{r}34.99 \\
(1.08) \\
\end{array}$ & $\begin{array}{r}34.99 \\
(1.08)\end{array}$ & 0.00 & 0.00 & --- & $\begin{array}{r}14.83 \\
(1.07)\end{array}$ \\
\hline $\begin{array}{l}\text { Not in LF, } \\
\text { want to work }\end{array}$ & $\begin{array}{l}29.25 \\
(1.68)\end{array}$ & $\begin{array}{l}29.25 \\
(1.68)\end{array}$ & 0.00 & 0.00 & --- & $\begin{array}{l}15.68 \\
(1.54)\end{array}$ \\
\hline $\begin{array}{l}\text { Not in LF, } \\
\text { retired }\end{array}$ & $\begin{array}{l}11.01 \\
(0.33)\end{array}$ & $\begin{array}{l}11.01 \\
(0.33)\end{array}$ & 0.00 & 0.00 & --- & $\begin{array}{l}23.34 \\
(1.51)\end{array}$ \\
\hline $\begin{array}{l}\text { Not in LF, } \\
\text { other }\end{array}$ & $\begin{array}{l}15.14 \\
(0.59)\end{array}$ & $\begin{array}{l}15.14 \\
(0.59)\end{array}$ & 0.00 & 0.00 & --- & $\begin{array}{l}16.87 \\
(1.33)\end{array}$ \\
\hline
\end{tabular}

Notes: Sample is all individuals in the SCE Job Search supplement aged 18-79 pooled across its 2013-2018 surveys. The desired hours gap is adjusted so that desired hours equal total work hours for employed individuals whose reported desired hours would otherwise imply a negative hours gap. Standard errors are in parentheses. 
Table 4. Desired Hours Gaps by Demographics and Broad Labor Force Status

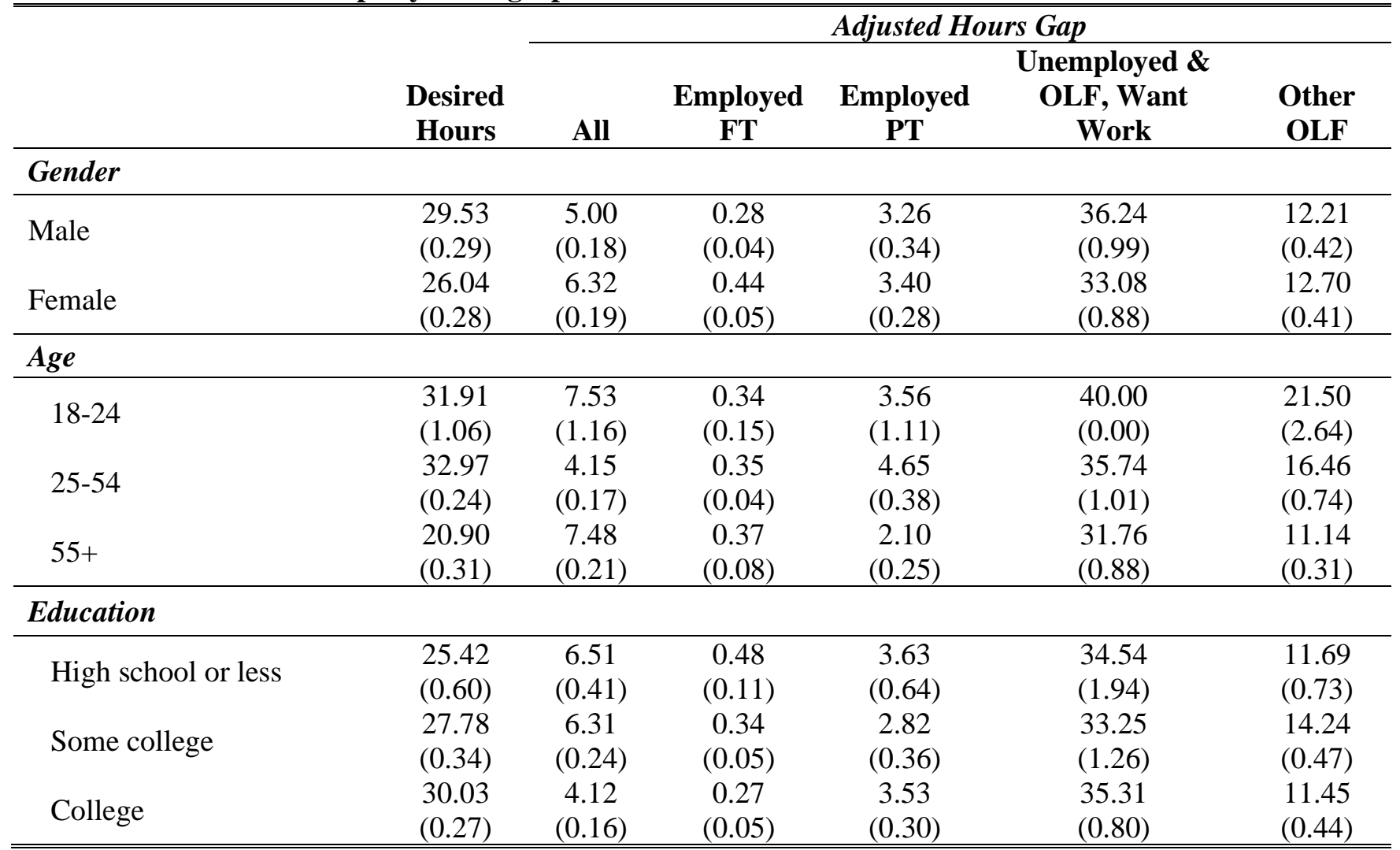

Notes: Sample is all individuals in the SCE Job Search supplement aged 18-79 pooled across its 2013-2018 surveys. The desired hours gap is adjusted so that desired hours equal total work hours for employed individuals whose reported desired hours would otherwise imply a negative hours gap. Standard errors are in parentheses. 
Dependent Variable: Incidence of actively searching for work in last four weeks

\begin{tabular}{|c|c|c|c|c|}
\hline & $(1)$ & (2) & (3) & (4) \\
\hline$\left(L_{i j}^{d}-h_{i j} \geq 0\right)$ & $\begin{array}{c}0.0088 \\
(0.0005)\end{array}$ & & & \\
\hline$\left(L_{i j}^{d}-h_{i j}<0\right)$ & $\begin{array}{l}-0.0133 \\
(0.0010)\end{array}$ & & & \\
\hline Employed $\times\left(L_{i j}^{d}-h_{i j} \geq 0\right)$ & & $\begin{array}{c}0.0217 \\
(0.0029)\end{array}$ & $\begin{array}{c}0.0210 \\
(0.0028)\end{array}$ & $\begin{array}{c}0.0208 \\
(0.0027)\end{array}$ \\
\hline Employed $\times\left(L_{i j}^{d}-h_{i j}<0\right)$ & & $\begin{array}{l}-0.0245 \\
(0.0030)\end{array}$ & $\begin{array}{l}-0.0235 \\
(0.0030)\end{array}$ & $\begin{array}{l}-0.0232 \\
(0.0029)\end{array}$ \\
\hline Unemployed $\times\left(L_{i j}^{d}-h_{i j}\right)$ & & $\begin{array}{c}0.0009 \\
(0.0008)\end{array}$ & $\begin{array}{l}-0.0002 \\
(0.0010)\end{array}$ & $\begin{array}{c}0.0006 \\
(0.0011)\end{array}$ \\
\hline $\mathrm{OLF} \times\left(L_{i j}^{d}-h_{i j}\right)$ & & $\begin{array}{c}0.0060 \\
(0.0007)\end{array}$ & $\begin{array}{c}0.0054 \\
(0.0007)\end{array}$ & $\begin{array}{c}0.0052 \\
(0.0007)\end{array}$ \\
\hline LFS fixed effects? & No & Yes & Yes & Yes \\
\hline Sex, age, education, year controls? & No & No & Yes & Yes \\
\hline $\begin{array}{l}\text { Race, marital status, HH children } \\
\text { controls }\end{array}$ & No & No & No & Yes \\
\hline$R$-squared & 0.060 & 0.194 & 0.212 & 0.221 \\
\hline
\end{tabular}

Dependent Variable: (archsinh of) Applications sent in last four weeks

(1)

(2)

(3)

(4)

$\begin{array}{lc}\left(L_{i j}^{d}-h_{i j} \geq 0\right) & 0.0195 \\ & (0.0019) \\ \left(L_{i j}^{d}-h_{i j}<0\right) & -0.0248 \\ & (0.0025)\end{array}$

Employed $\times\left(L_{i j}^{d}-h_{i j} \geq 0\right)$

$\begin{array}{lll}0.0373 & 0.0366 & 0.0360\end{array}$

Employed $\times\left(L_{i j}^{d}-h_{i j}<0\right)$

$(0.0062)$

$(0.0061)$

$(0.0060)$

$-0.0382$

$-0.0371$

$-0.0364$

Unemployed $\times\left(L_{i j}^{d}-h_{i j}\right)$

$(0.0065)$

$(0.0064)$

$(0.0063)$

$\mathrm{OLF} \times\left(L_{i j}^{d}-h_{i j}\right)$

0.0058

0.0042

0.0041

(0.0152)

$(0.0147)$

$(0.0148)$

0.0106

0.0096

0.0092

LFS fixed effects?

Sex, age, education, year controls?

(0.0019)

Race, marital status, $\mathrm{HH}$ children

controls?

$\begin{array}{ll}\text { No } & \text { Yes } \\ \text { No } & \text { No } \\ \text { No } & \text { No }\end{array}$

(0.0019)

(0.0019)

\begin{tabular}{lllll}
\hline$R$-squared & 0.068 & 0.243 & 0.256 & 0.268 \\
\hline \hline
\end{tabular}

Notes: Table reports estimates from regressing the listed measure of search effort on the desired hours gap (desired hours - usual hours worked) for our sample respondents from the SCE Job Search supplement pooled over 2013-18 $(N=6,314)$. Age controls are three categories for ages 18-24, 25-54, and 55+. Education controls are three categories for those with a high school degree or less, some college, or a college degree or more. Race controls are categories for while (non-Hispanic), black (non-Hispanic), Hispanic, and all other. Household children controls are separate counts for the number of children under 6 and between 6 and 17 years old. Standard errors are clustered by state and year and listed in parentheses. 
Table 6. National-Level Relationships between Wage Growth and of Measures of Labor Market Underutilization

Dependent Variable: Year-over-Year Growth of Median Hourly Wage

\begin{tabular}{|c|c|c|c|c|c|c|c|}
\hline & $(1)$ & (2) & (3) & (4) & $(5)$ & (6) & (7) \\
\hline Unemployment Rate & $\begin{array}{l}-0.555 \\
(0.133)\end{array}$ & & & & & & \\
\hline $\begin{array}{l}\text { Unemployment Rate } \\
\text { Gap }\end{array}$ & & $\begin{array}{l}-0.620 \\
(0.147)\end{array}$ & & & & & \\
\hline Short-Term & & & -0.524 & & & & \\
\hline Unemployment & & & $(1.618)$ & & & & \\
\hline Medium Term & & & 0.141 & & & & \\
\hline Unemployment & & & $(1.004)$ & & & & \\
\hline Long-Term & & & -1.066 & & & & \\
\hline Unemployment & & & $(0.500)$ & & & & \\
\hline DFH-JOLTS Quits & & & -0.124 & & & & \\
\hline Rate & & & $(0.551)$ & & & & \\
\hline $\begin{array}{l}\text { HKL Nonemployment } \\
\text { Index }\end{array}$ & & & & $\begin{array}{r}-0.799 \\
(0.156)\end{array}$ & & & \\
\hline FMST Total Slack & & & & & -0.511 & & \\
\hline Measure & & & & & $(0.104)$ & & \\
\hline $\begin{array}{l}\text { FMST Total Slack, } \\
\text { Detrended }\end{array}$ & & & & & & $\begin{array}{l}-0.567 \\
(0.116)\end{array}$ & \\
\hline FMST E Slack & & & & & & & -4.984 \\
\hline Component & & & & & & & $(2.543)$ \\
\hline FMST U Slack & & & & & & & -0.387 \\
\hline Component & & & & & & & $(0.177)$ \\
\hline FMST $N$ Slack & & & & & & & -0.473 \\
\hline Component & & & & & & & $(0.218)$ \\
\hline$D-W$ Statistic & 1.908 & 1.899 & 1.891 & 1.932 & 1.901 & 1.929 & 1.984 \\
\hline Adjusted $R$-squared & 0.123 & 0.126 & 0.082 & 0.191 & 0.174 & 0.174 & 0.238 \\
\hline Root MSE & 0.424 & 0.425 & 0.427 & 0.421 & 0.420 & 0.420 & 0.419 \\
\hline
\end{tabular}

Notes: Table reports estimates from regressing wage growth on the listed measures of labor market underutilization using quarterly data for 1995Q1-2018Q4 $(N=96)$. Wage growth is measured as the four-quarter moving average of the quarterly mean of monthly year-over-year changes in the median hourly wage, which we estimate from the CPS. The unemployment rate is the standard measure from the BLS, and the unemployment rate gap is the difference between the unemployment rate and the short-run NAIRU estimated by the Congressional Budget Office. Short-term, medium-term, and long-term unemployment refers to the fraction of the labor force that has been unemployed for up to five weeks, five to 26 weeks, or over 26 weeks, respectively. The DFH-JOLTS quit rate is the quarterly estimate of worker quits from Davis, Faberman, and Haltiwanger (2012), where we extend their estimates through 2018. The AHG measure (and its components) is the quarterly average of the measure constructed in this paper. The detrended AHG measure is the same measure less its demographic trend. All underutilization measures use a four-quarter moving average in the regression. The model is estimated using maximum likelihood and a three-lag autoregressive error structure. Standard errors are reported in parentheses. 
Table 7. State-Level Relationships between Wage Growth and of Measures of Labor Market Underutilization Dependent Variable: Year-over-Year Growth of Median Hourly Wage

$(1)$

$-0.385$

Unemployment Rate

FMST Total Slack

Measure

FMST $E$ Slack

Component

FMST $U$ Slack

Component

FMST $N$ Slack

Component

\begin{tabular}{lcccccc}
\hline State effects? & Yes & Yes & Yes & Yes & Yes & Yes \\
Time effects? & Yes & Yes & Yes & No & No & No \\
\hline Adjusted $R$-squared & .172 & .172 & .179 & .125 & .141 & .148 \\
\hline Root MSE & 2.367 & 2.368 & 2.357 & 2.434 & 2.411 & 2.402 \\
\hline
\end{tabular}

Notes: Table reports estimates from regressing wage growth on the listed measures of labor market underutilization using quarterly state-level data for 1995Q1-2018Q4 $(N=4,896)$. Wage growth is measured as the four-quarter moving average of the quarterly mean of monthly year-over-year changes in the median hourly wage, which we estimate from the CPS. The unemployment rate is the standard measure from the BLS. The AHG measure (and its components) is the quarterly average of the measure constructed in this paper. Standard errors are clustered by state and quarter and are reported in parentheses. 
Figure 1. Histograms of Desired Hours Gaps by Detailed Labor Force Status

Employed FT, Single Job

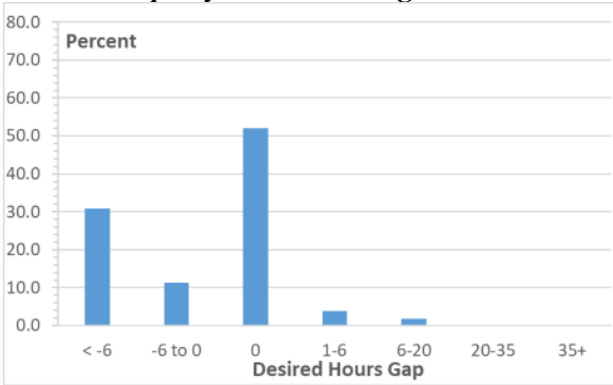

Employed PT, Multiple Jobs

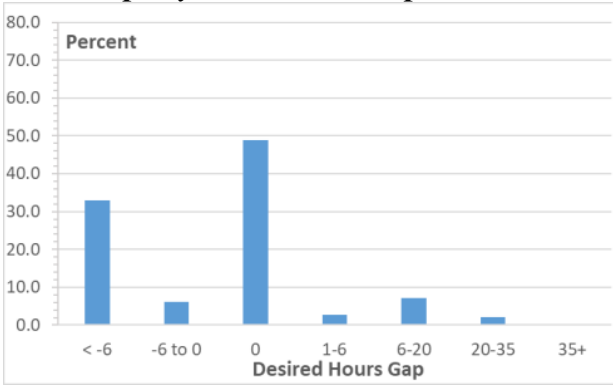

OLF, Want Work

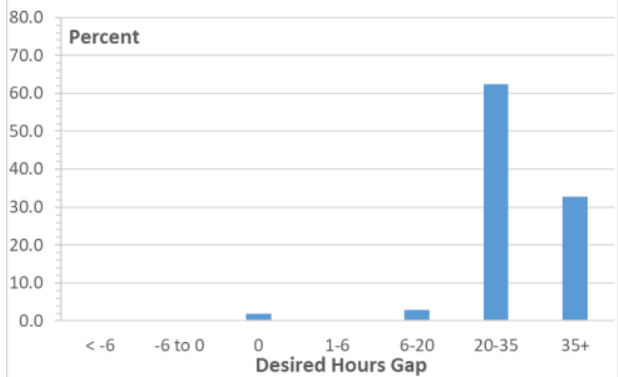

Employed FT, Multiple Jobs

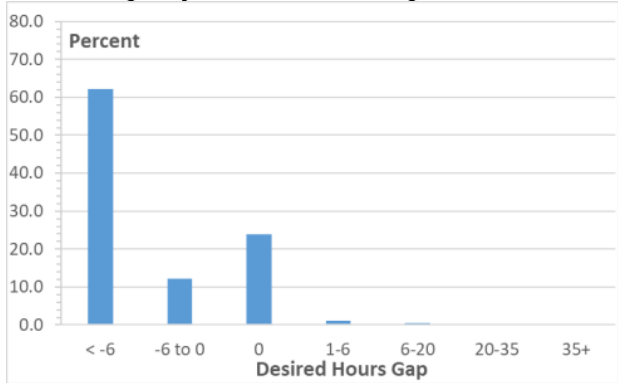

Unemployed $\leq 6$ Months

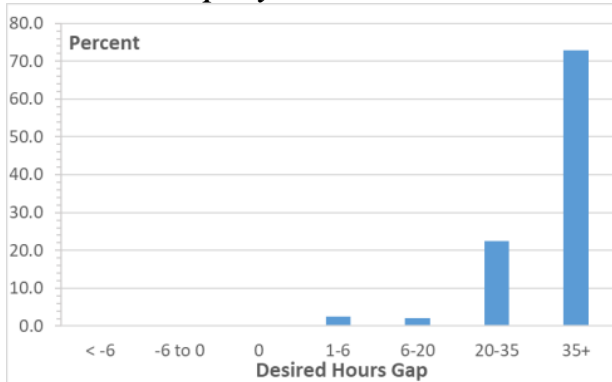

OLF, Retired

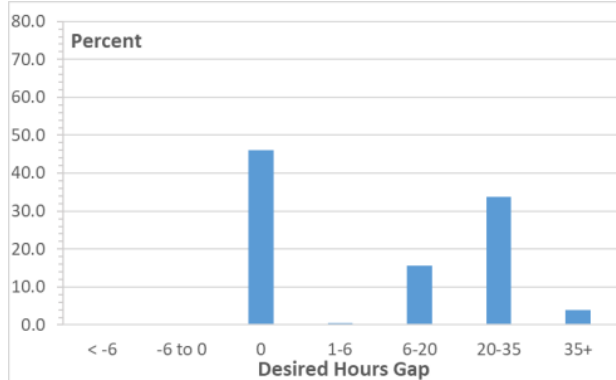

Employed PT, Single Job

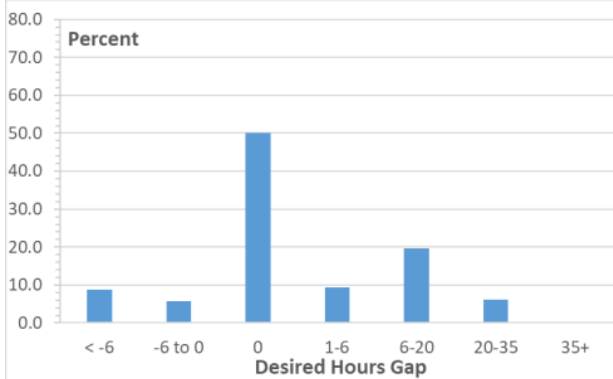

Unemployed > 6 Months

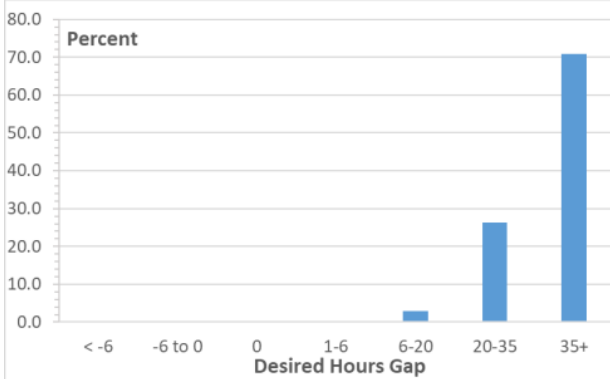

OLF, Other

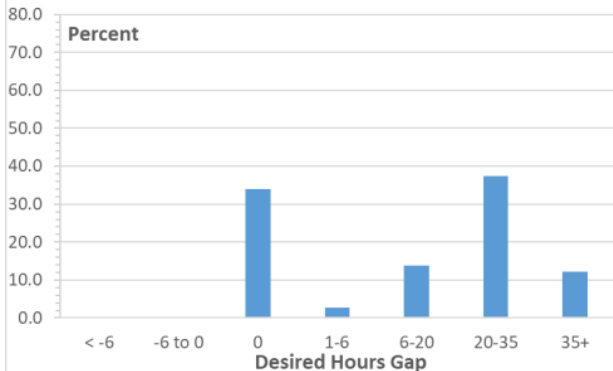

Notes: Histograms report the desired work hours gaps separately by each listed labor force state and include a separate category for those with a gap of exactly zero. Sample is individuals aged 18-79 from the SCE Job Search supplement pooled across its 2013-2018 surveys. 
Figure 2. The Aggregate Hours Gap and its Broad Components

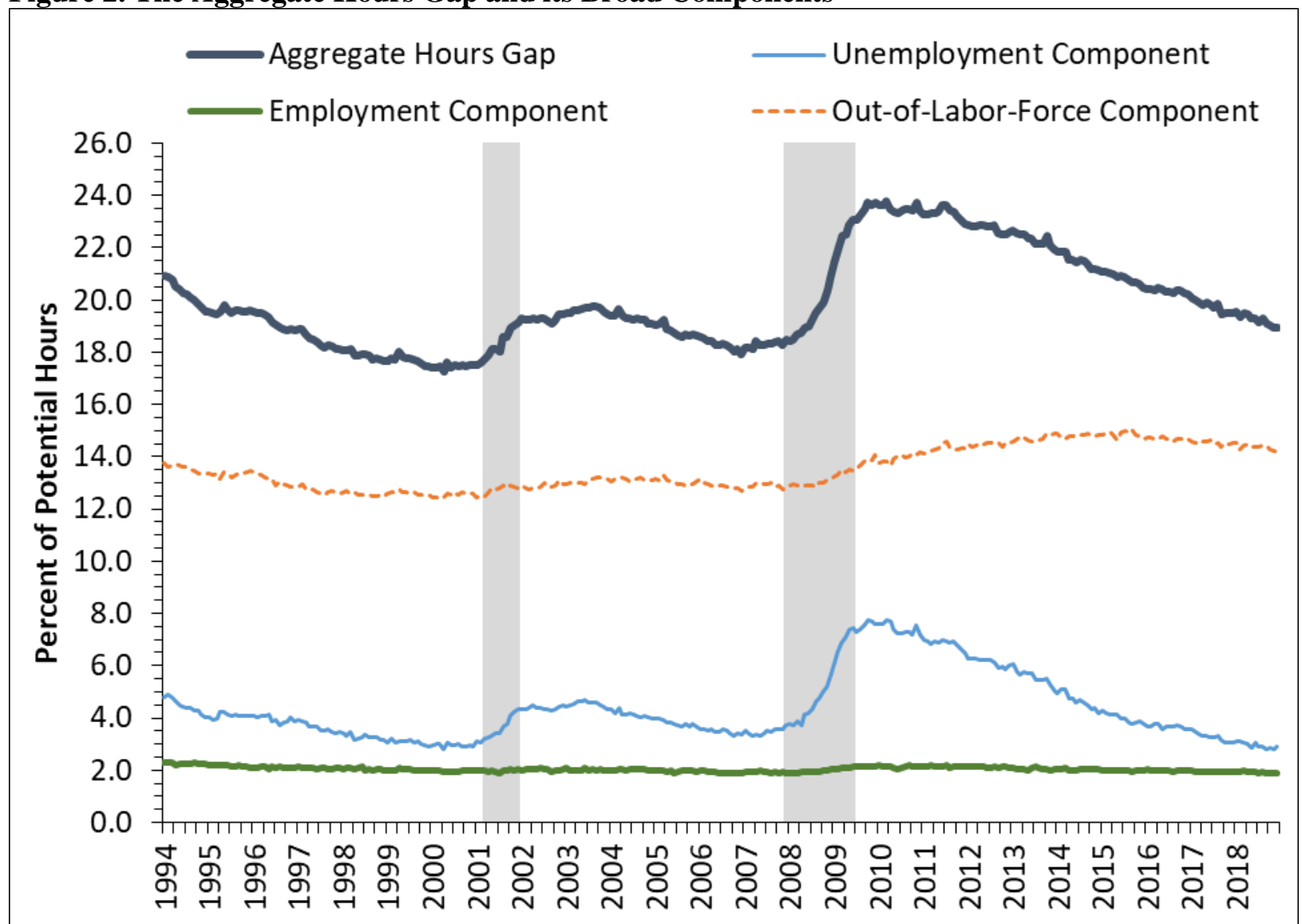

Note: Estimates are for all individuals aged 18-79 from the Current Population Survey. The AHG measure is described in the text. The employment, unemployment and out-of-the-labor-force components are the contributions of each to the AHG measure, measured as a percentage of the (desired hours-weighted) population. See text for details. 
Figure 3. The Aggregate Hours Gap, Detailed Components

(a) Employment and Detailed Nonemployment Components

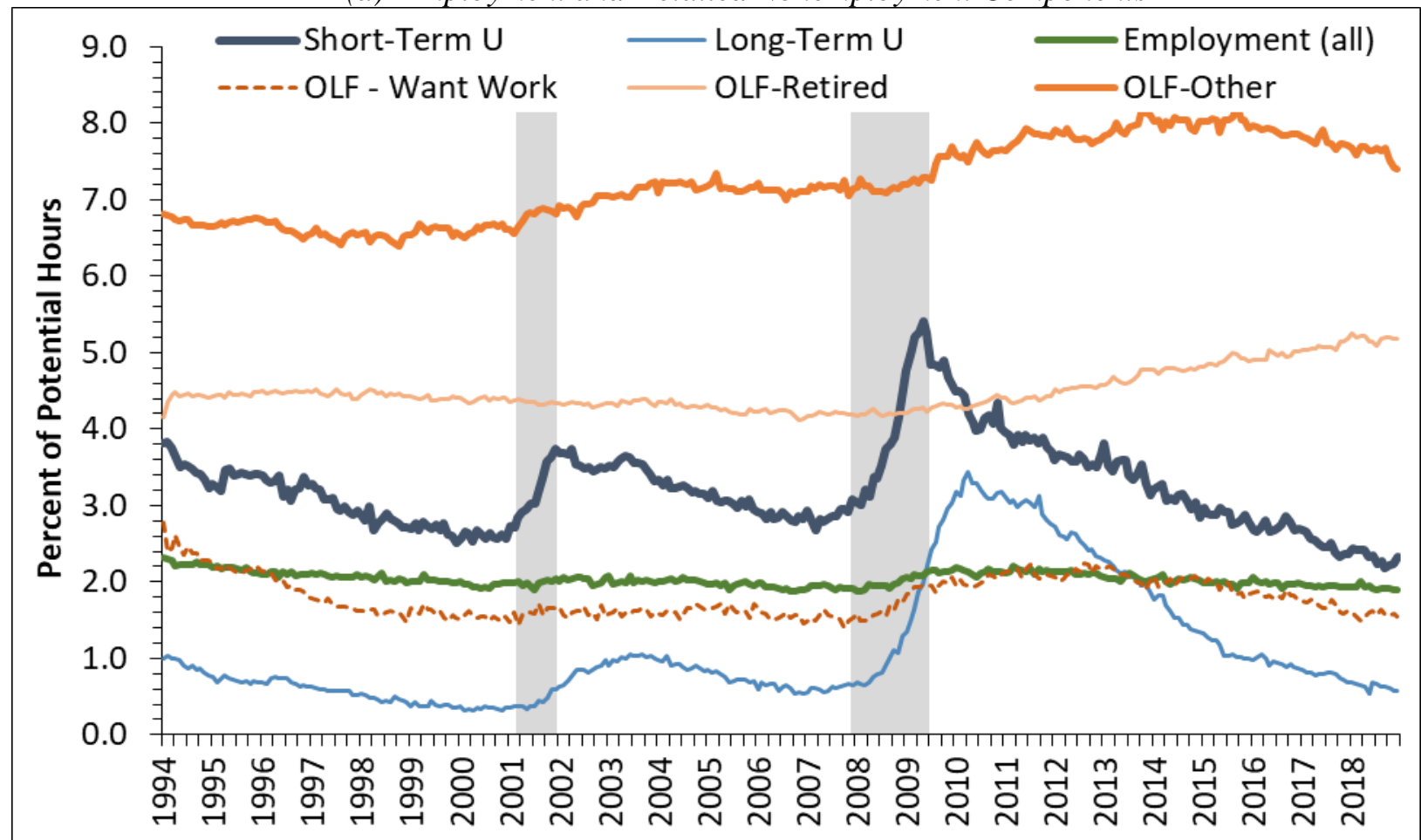

(b) Detailed Employment Components

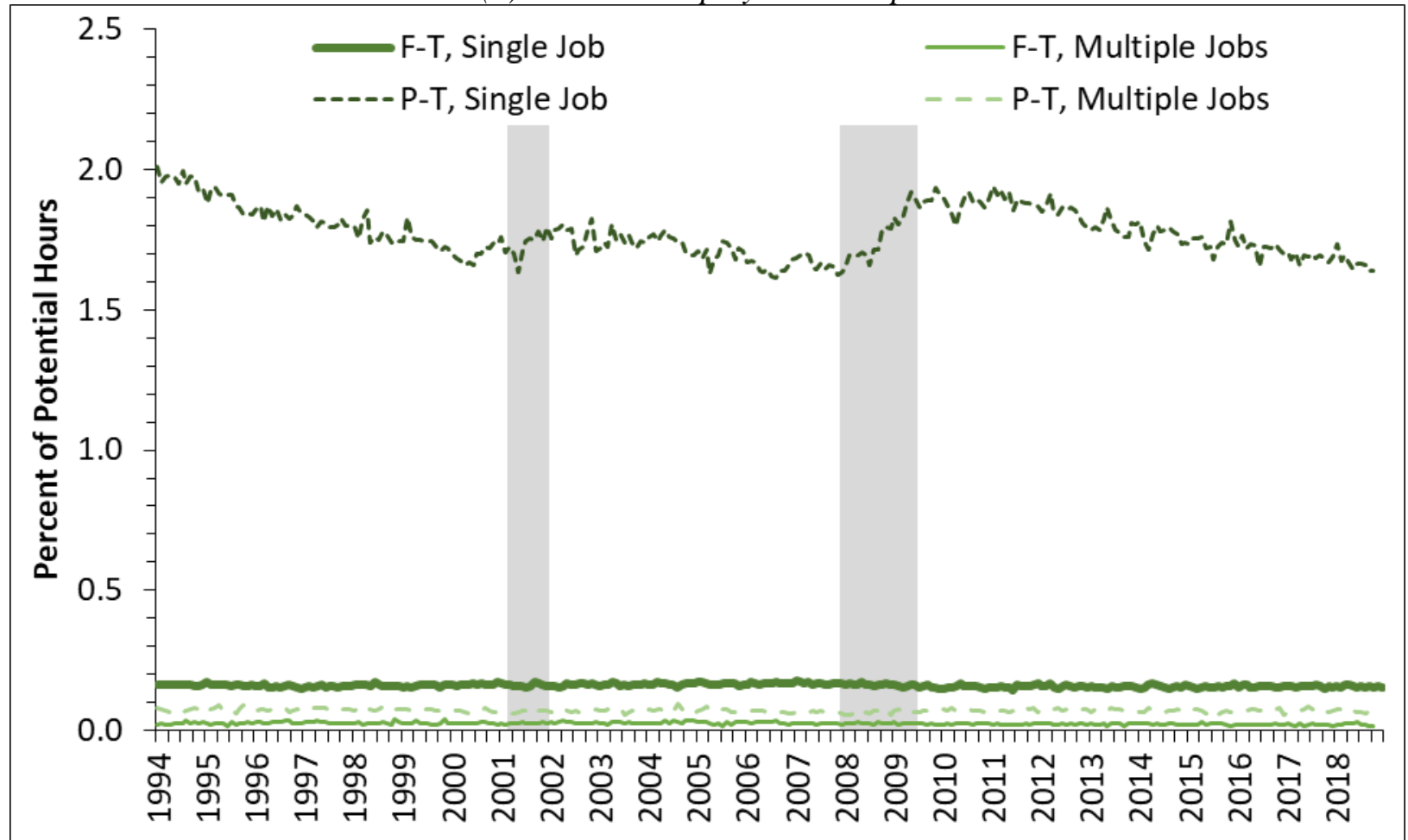

Note: Estimates are for all individuals aged 18-79 from the Current Population Survey. The AHG measure is described in the text. The individual labor force status components are the contributions of each to the AHG measure, measured as a percentage of the (desired hours-weighted) population. See text for details. 
Figure 4. Unemployment vs. the Aggregate Hours Gap

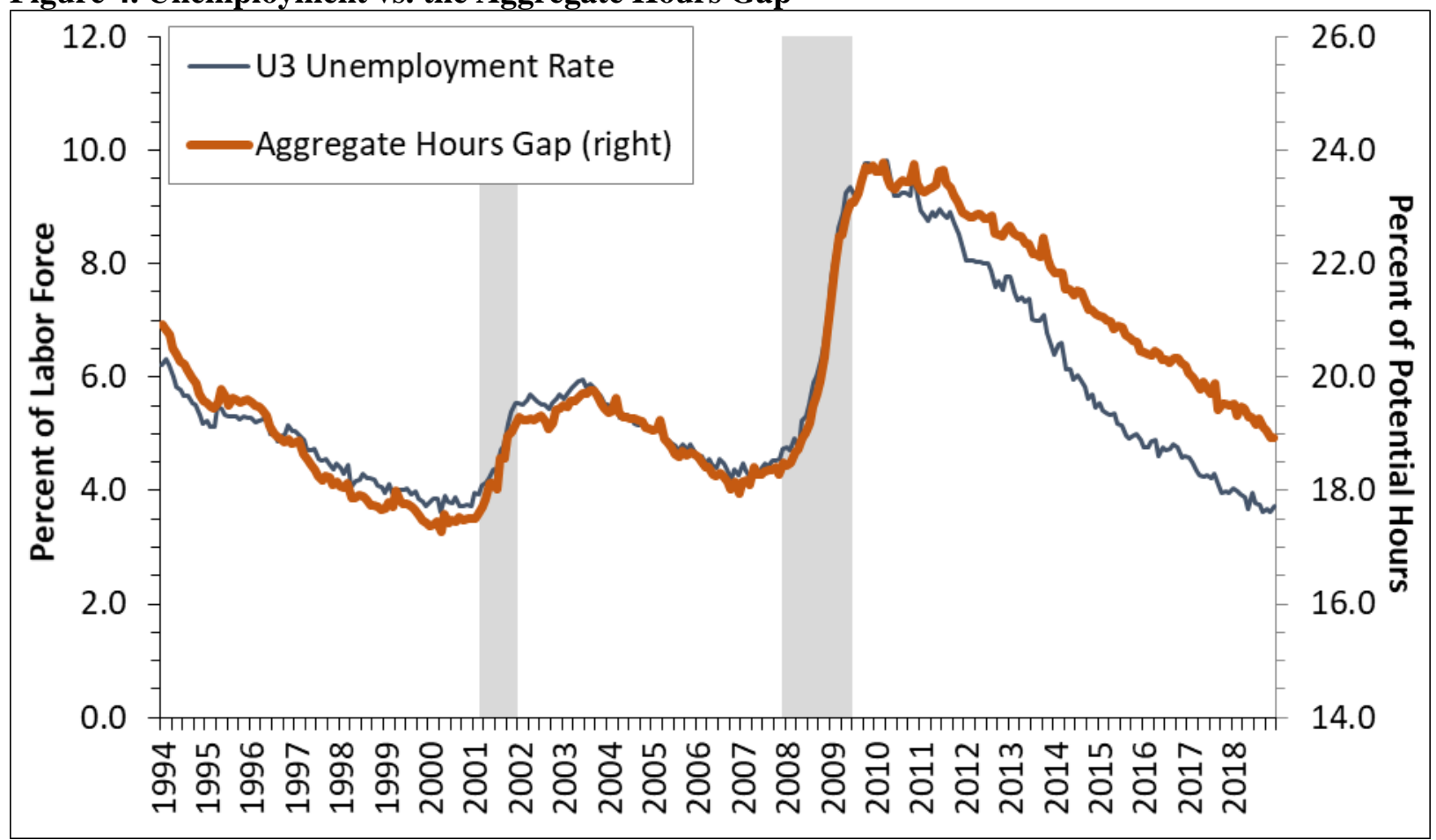

Note: Estimates are for all individuals aged 18-79 from the Current Population Survey. The U3 measure is the official BLS unemployment rate measure. The AHG measure is described in the text.

Figure 5. Differences in Selected Measures of Labor Market Underutilization

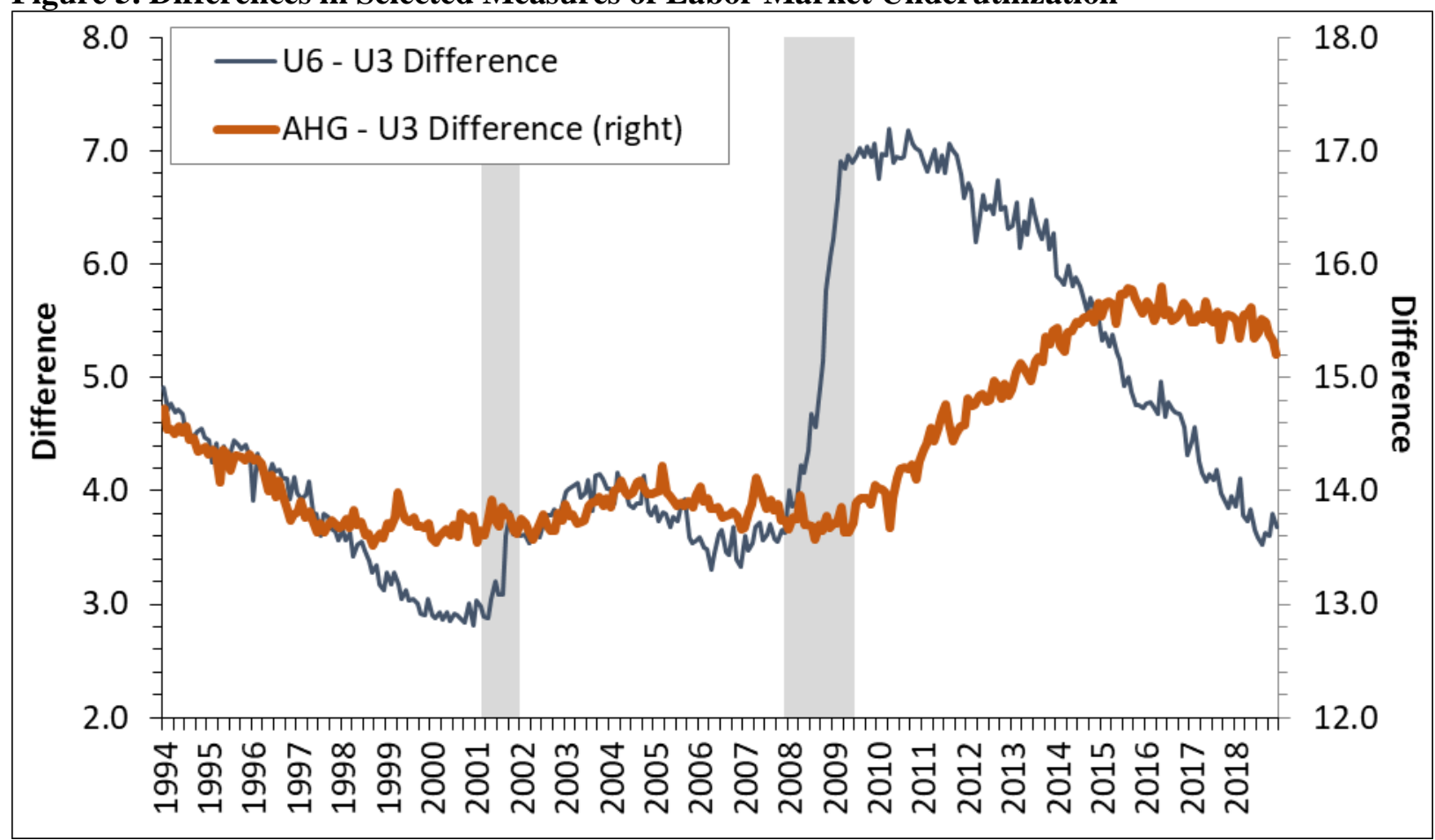

Note: Estimates are for all individuals aged 18-79 from the Current Population Survey. The U3 measure is the official BLS unemployment rate measure. The U6 measure additionally includes those marginally attached to the labor force and those employed part-time for economic reasons. The AHG measure is described in the text. 


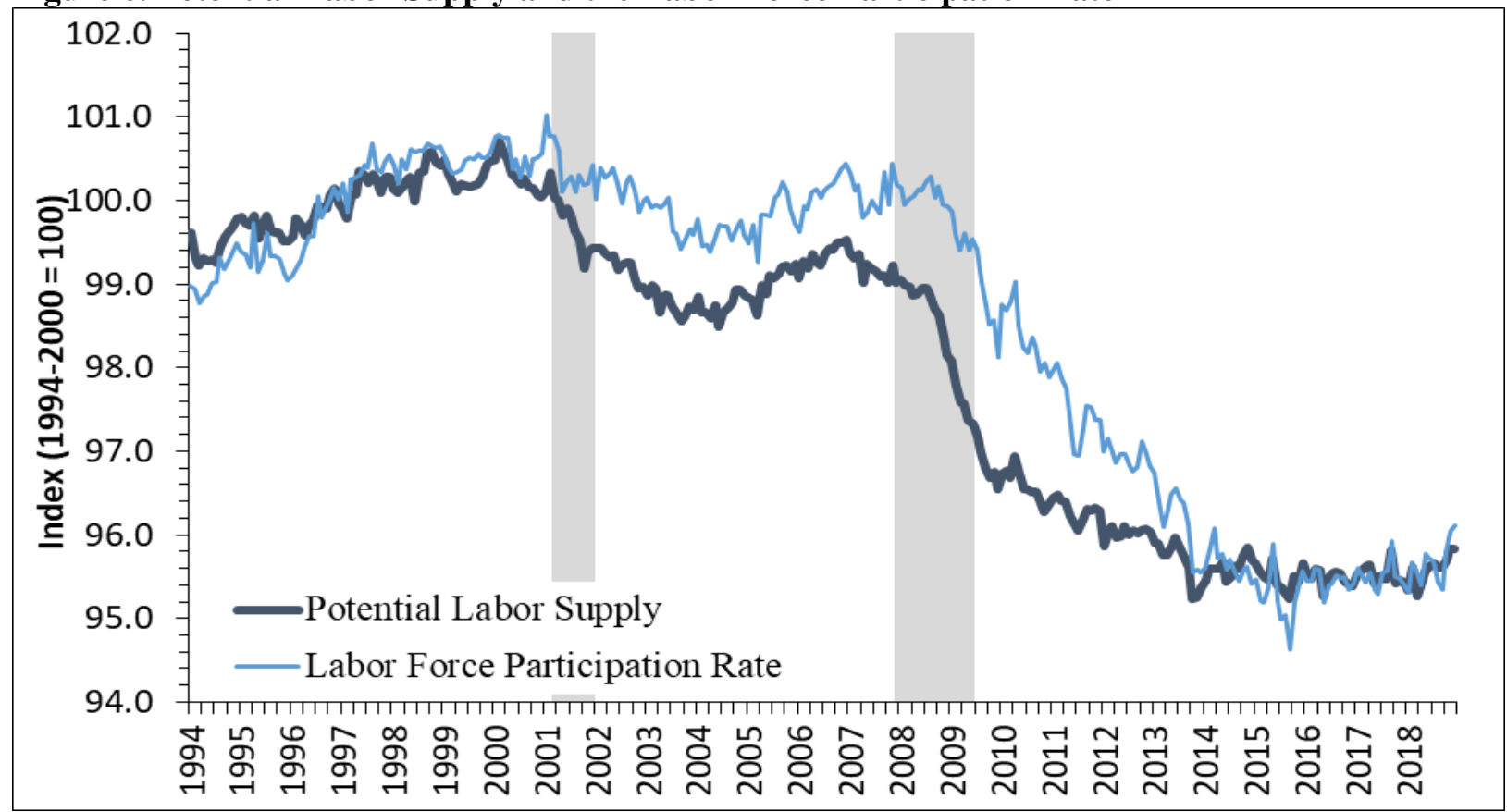

Note: Estimates are for all individuals aged 18-79 from the Current Population Survey. The labor force participation rate is the share of the population that is employed or unemployed. Potential labor supply is the average number of desired work hours across all individuals. See text for more details on its estimation.

Figure 7. The Aggregate Hours Gap and its Demographic Trend

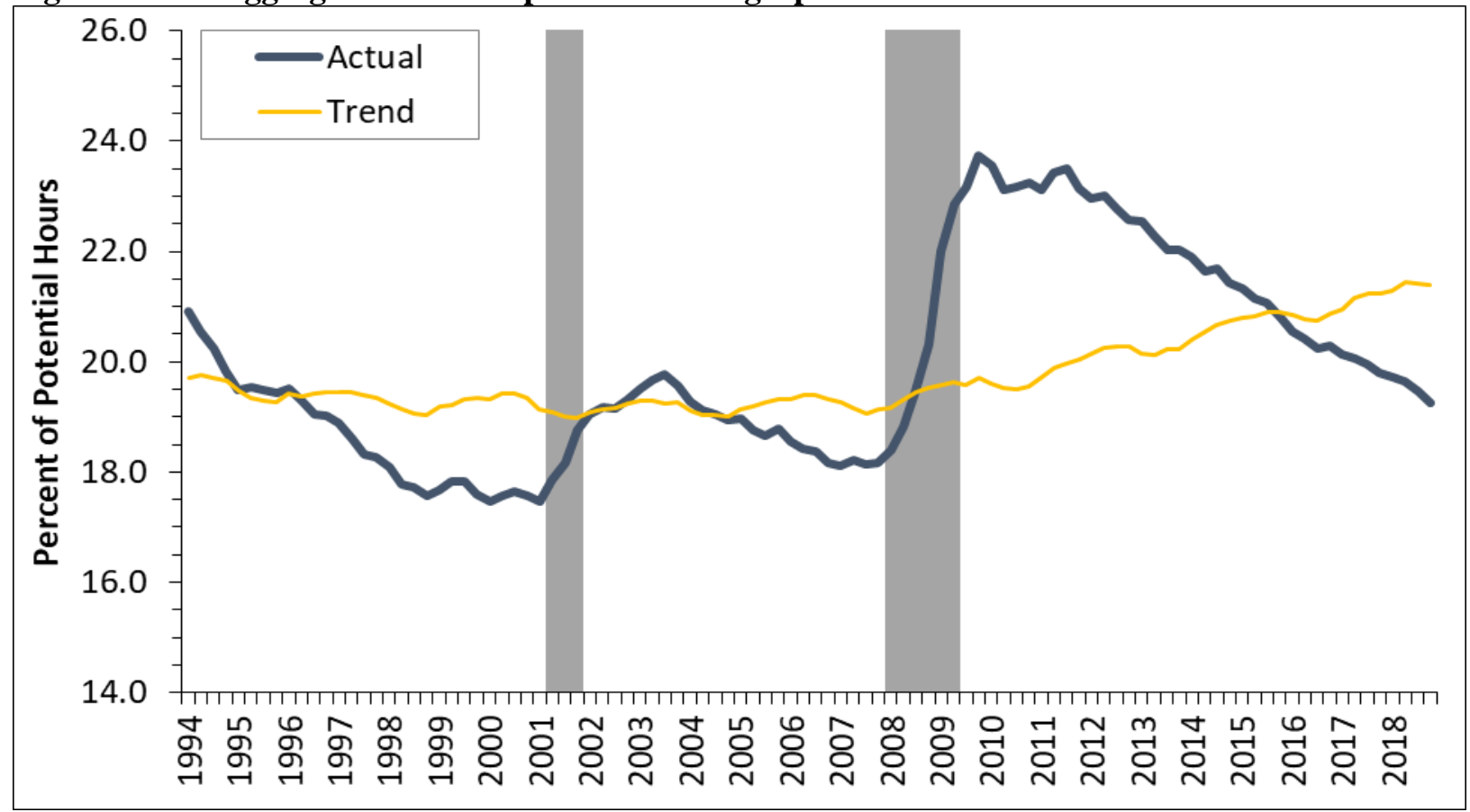

Note: Estimates of our AHG measure are for all individuals aged 18-79 at the quarterly frequency. Its estimation is described in the text. The demographic trend captures movements in the AHG measure net of the movements in the population shares of our detailed labor market states predicted by their relationship with state-level unemployment rate gaps. Our methodology for trend estimation is also described in the text. 
Figure 8. Potential Labor Supply and its Demographic Trend

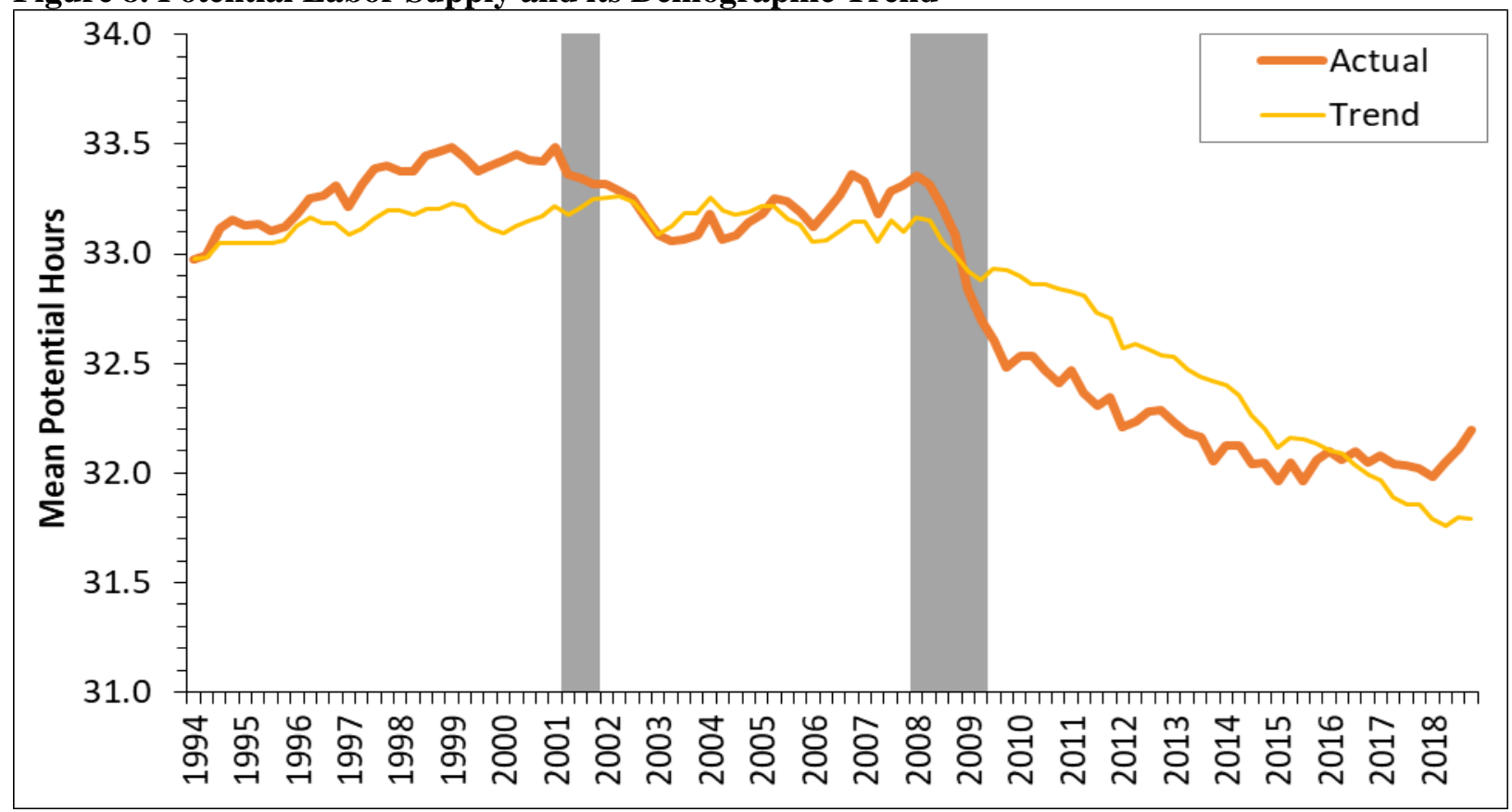

Note: Estimates of potential labor supply are mean desired work hours for all individuals aged 18-79, at the quarterly frequency. Its estimation is described in the text. The demographic trend captures movements in potential labor supply net of the movements in the population shares of our detailed labor market states predicted by their relationship with state-level unemployment rate gaps. Our methodology for trend estimation is also described in the text.

Figure 9. State-Level Comparisons of Unemployment vs. the Aggregate Hours Gap

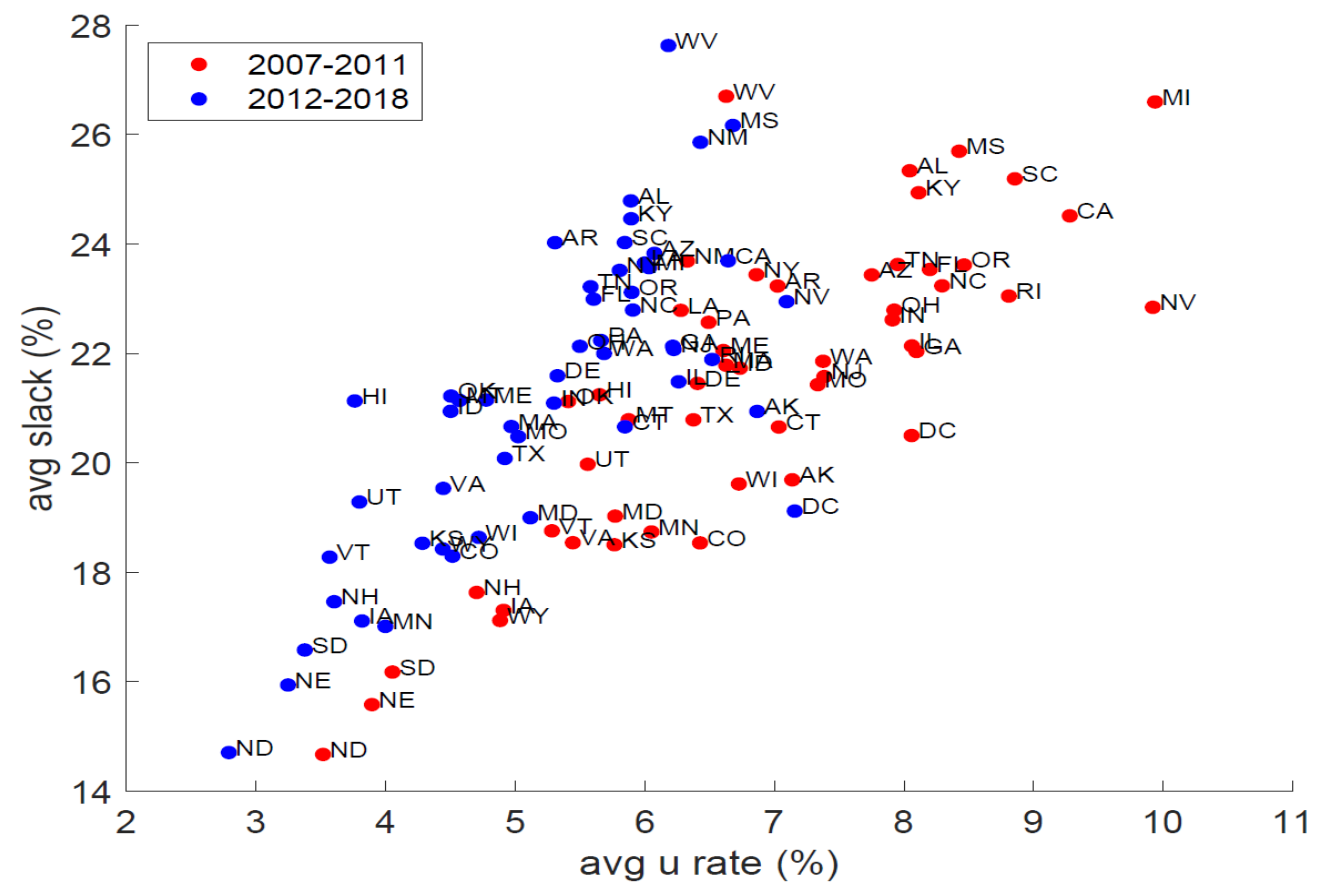

Note: The figure plots the average value of our AHG measure versus the average unemployment rate for each state over the listed time periods (2007-11, red; 2012-18, blue). See text for details of the AHG measure's estimation. 


\section{Appendix}

\section{Appendix A. Desired Hours by Demographics and Labor Force Status}

Our estimation of the Aggregate Hours Gap relies on estimates of desired work hours by detailed demographics and labor force status. We generate these estimates from pooled data across survey years of the SCE Job Search supplement. The estimates are for nine different labor force states (as noted in the main text), three age groups (less than 25, 25 to 54, 55 or older), gender, and two education groups (less than a college degree or a college degree or more). This creates a potential for up to 108 group estimates of desired work hours. Unfortunately, sparse sample cells limit our ability to generate reliable estimate for all 108 groups. Consequently, we aggregate individuals into 39 broader groups. These groups are an unbalanced panel of demographic subgroups across the nine labor force states. That is, each labor force state has a different number of demographic groups that depends on several factors. The first is the overall size of the labor force state. Smaller states, such as the unemployed and those out of the labor force but want work, have fewer demographic groups. All labor force states disaggregate at least by gender. We disaggregate further by education, age, or both where possible. The criteria we use in determining which groups to aggregate and to what degree are sample cell size and the similarity in mean desired work hours among the groups - in general we try to only aggregate groups with similar desired hours and hours gap estimates.

Table A.1 reports the mean desired hours and (adjusted) hours gaps for the 39 demographics $\times$ labor force status categories that we use in the estimation of our measure of labor market underutilization. These categories represent the finest level of disaggregation we feel we can use given the sample size constraints. The table shows considerable heterogeneity in desired 
hours and hours gaps across the groups. Consistent with the evidence in Tables 4 and 5 in the main text, full-time workers prefer greater hours than part-time workers, those out of the labor force prefer fewer hours than those in the labor force, men tend to prefer more hours than women, the college educated tend to prefer more hours than those without a college degree, and older workers tend to prefer fewer hours than prime-aged and younger workers.

\section{Appendix B. Additional Estimates and Robustness}

\section{B.1. Additional Estimates of Desired Hours and Transition Rates}

We report additional estimates of desired hours from the SCE data. Table B.1 reports average desired hours and (adjusted) hours gaps by marital status and race, building upon Table 3 in the main text. It shows that, on average, married individuals prefer more work hours than single individuals. The difference is a statistically significant 2.0 hours per week. At the same time, the gap between desired and actual work hours for married individuals is about 1.5 hours per week smaller than the hours gap for single individuals. The overall gap is driven entirely by differences in the labor force composition of married and single individuals, as their estimated hours gaps within broad labor force categories are roughly equal. The one exception is among the unemployed, where married individuals exhibit a larger hours gap. White, non-Hispanic individuals desire significantly fewer hours and also have smaller hours gaps than non-whites. On average, white individuals prefer about 27.0 hours per week, compared to 30.2 hours per week preferred by black individuals, 31.0 hours per week preferred by Hispanics, and 29.1 hours per week preferred by other races. Blacks have a significantly higher desired hours gap relative to others, averaging 7.1 hours per week, compared to 5.5 hours per week for whites, 5.8 hours per week for Hispanics, and 5.1 hours per week for other races. This is true overall and within most 
labor force states. The one exception is among the unemployed, where blacks desire fewer hours than the other groups, though the differences are not statistically significant.

Figure B.1 reports the distribution of desired hours gaps by detailed labor force status. It is identical to Figure 1 in the main text except that the hours gaps are adjusted to have a minimum value of zero for the employed. As one can see, adjusted hours gaps are zero for nearly all workers except those working part-time in a single job.

Finally, Table B.2 reports job-to-job transition rates for individuals by the type of initial and new job. Part-time workers and multiple jobholders have considerably higher job-to-job transition rates than full-time and single jobholders, but transitions into multiple jobholding by single jobholders are notable as well, with about 1.3 percent of full-time workers and 2.0 percent of part-time workers becoming multiple jobholders in any given month. In fact, job-finding rates for single jobholders are about 60 percent higher when we account for jobs added as an additional job (rather than switch to a new main job).

\section{B.2. Validating Desired Hours as a Measure of Potential Labor Supply}

Figure B.2 shows the link between the reported desired hours gap and reported search effort graphically. It corresponds to the regression results we report in Table 5 of the main text. The figure reports the mean levels of search effort for discrete categories of desired hours. We include a separate category for individuals with a desired hours gap of zero. The top panels report the means for all individuals pooled together, where we condition out the effects of broad labor force status (employed, unemployed, or out of the labor force). The bottom panels report the means separately for each broad labor force state. The left panels report the fraction of individuals who actively searched within each bin, while the right panels report the (mean) inverse hyperbolic sine of the number of applications sent within each bin. All four panels show that search effort rises 
with the desired hours gap. This is true whether we look at the incidence of active search or the intensity of search effort (i.e., applications sent). It is also true within labor force states, particularly for the employed and those out of the labor force. Keep in mind that nearly all unemployed search by definition, and while the unemployed exhibit a U-shaped pattern in their mean applications sent, there are very few observations of unemployed with a desired hours gap of less than 20 hours (see Figure 1 of the main text and Figure B.1 in this appendix).

\section{B.3. Robustness}

We also consider alternate approaches to estimating the Aggregate Hours Gap (AHG) measure. First, we evaluate how much our measure differs if we use actual hours worked in the previous week rather than usual hours worked, as reported in the CPS. Next, we evaluate how much using only three labor market states (employed, unemployed, or out of the labor force) rather than our nine detailed states matters. We do this with and without the additional disaggregation by demographics. Then, we evaluate the performance of using time-varying estimates of desired hours derived from an out-of-sample prediction based on our demographics $\times$ labor force status groups and measures of aggregate labor market tightness and individual hours. Finally, we evaluate how the AHG measure compares to the unemployment rate among prime-aged males.

Figure B.3 reports the estimates for the AHG measure using actual hours and using only three labor market states. When using only the three labor market states, we repeat the exercise using an additional disaggregation by demographics within each of the three states and ignoring demographics entirely. As in the main text, we use an unbalanced grouping of demographic groups across the states to minimize the effects of small sample cells. This generates a total of 22 rather than 39 demographics $\times$ labor force status groups. By construction, the exercise that ignores demographics only uses three groups. As a benchmark, we also include our baseline measure from 
the main text. In general, all three alternate estimates exhibit the same time-series behavior, but with notably higher levels of estimated labor market slack, relative to the baseline estimates. Using actual hours produces a larger and noisier measure of underutilization relative to the baseline. Actual hours worked are more likely to capture vacations, paid leave, and other work absences, and therefore will generate larger hours gaps among the employed. There are also occasional spikes in the measure using actual hours. These are predominantly driven by major strikes and other work stoppages during our sample period. Using only three labor force states also produces a higher estimate of the level of slack, but is otherwise similar to our baseline measure. The higher level comes from the fact that we treat the desired hours of full-time and part-time works as an average between the two. Consequently, nearly all of the full-time employed have their desired hours understated and are assigned a zero hours gap, and many of the part-time employed have their desired hours overstated and are assigned a larger hours gap than we get when account for the full-time/part-time heterogeneity in the baseline measure. The difference in magnitudes relative to the baseline is less pronounced when we ignore demographics, but the three-state measure that ignores demographics also predicts a relatively more sluggish decline in the slack measure following the Great Recession. This is mostly because it imposes the average behavior of the retired on all of those out of the labor force, and does so to a greater degree when we ignore demographic differences within each state.

Next, we estimate the AHG measure using a time-varying measure of desired hours. We estimate time-varying desired hours using out-of-sample predicted estimates, and derive these estimates from the relationship between reported desired hours, hours worked, and aggregate labor market variables observed within the SCE data. Specifically, we estimate the following using the SCE data, 


$$
L_{i j t}=\alpha_{d j}+\beta_{d j} \hat{u}_{s t}+\gamma_{d j}^{f} h_{s t}^{f}+\gamma_{d j}^{p} h_{s t}^{p}+\theta h_{i j t}+\eta_{i j t}
$$

That is, we regress desired hours $L_{i j t}$ on a set of fixed effects for our 39 demographics $\times$ labor force categories, $\alpha_{d j}$, the 39 categories interacted with our measure of the state-level unemployment gap (measured identically to the one used in the wage equations estimated in main text), $\hat{u}_{s, t}$, the 39 categories interacted with the state-level mean hours worked by full-time and part-time workers, $h_{s t}^{f}$ and $h_{s t}^{p}$, respectively (averaged to the quarterly frequency), and the reported total usual hours worked by the respondent, $h_{i j t}$. To account for sampling and measurement differences between the SCE and CPS survey, we instrument $h_{i j t}$ with the mean total usual hours worked by our 39 demographic $\mathrm{x}$ labor force categories, estimated as their quarterly average over the survey period for each year of the SCE survey. We then take the coefficients from the second stage of a two-stage least squares estimation of (A1) and interact them with the state-level labor market variables and total usual hours reported by individuals in the CPS to get a predicted timevarying measure of desired hours. We then apply our methodology from Section 5.1 of the main text, replacing the time-invariant $L_{d(i) j}$ measure of desired hours with the predicted, time-varying $\widehat{L}_{d(i) j t}$ estimate.

The results of the exercise are in Figure B.4. The AHG measure that uses time-varying desired hours shows somewhat more cyclicality during the 1990s, suggesting a lower degree of labor market slack than our baseline measure during this period. It predicts roughly the same amount of slack between then and the Great Recession. During and after the Great Recession, however, it predicts a much higher degree of labor market underutilization, but also less sluggishness in its recovery following the recession, though it, too, remains above its pre-recession levels at the end of 2018. Despite the interesting differences between estimates using the timevarying and time-invariant measures, a few caveats are in order. First, the sample size of the SCE 
is relatively small and its frequency is annual. Its time series is also short, with only six periods of observations between 2013 and 2018. Furthermore, there was little cyclical variation in the U.S. labor market, save for a gradual improvement in conditions, over this period. Consequently, our prediction exercise does not have the predictive power of one that benefits from a larger sample or richer time-series variation. There is also the issue that we only have existing measures of labor market underutilization available to generate the predicted time-series variation in desired hours. If the true (i.e., unobserved) variation in desired hours differs from what is predicted by the unemployment rate gap, our predicted exercise will fail to capture these movements. Consequently, we use the time-invariant estimates in our baseline measure since these rely on the direct reporting of desired hours and no assumptions on the relationship between the time-series behavior of desired hours and existing measures of labor market underutilization. The results in Figure B.4 suggest that this leads to a potential understatement of the cyclicality of labor market slack from our baseline measure.

Finally, we compare the behavior of the AHG measure to the unemployment rate, restricting the sample to prime-aged males (age 25 to 54). Figure B.5 reports the results of this exercise, and is a replication of Figure 4 in the main text for this subgroup. As with the comparison for the full population in Figure 4, our baseline measure shows a greater degree of slack that the unemployment rate at the end of our sample period. The differences, however, are much smaller. From its peak to the end of 2018, the unemployment rate for prime-aged males falls by 5.9 percentage points, while our measure of underutilization falls by 5.6 percent. In addition, our measure for prime age males returns to its pre-recession level for prime-aged men by the end of 2018, which is not the case for the full population. The differences between the results in Figure B.5 and the results in Figure 4 suggest that workers other than prime-age males account for the 
additional sluggishness that we see for the full population. This is not surprising since much of the disparity appears driven by retirees and others outside of the labor force in Figure 5 of the main text.

\section{B.4. The Role of Demographics}

Figure B.6 reports the results of estimating the contribution of broad demographic groups to our aggregate AHG measure. We present the results separately by age, gender, and education group, splitting up each category as we do within each labor force state when estimating the AHG measure. That is, we report the contributions of three age groups (18 to 24, 25 to 54, and 55 to 79), men and women, and two education groups (less than a college degree and college or more). The contributions are equal to the AHG measure calculated for each demographic group multiplied by that group's population share.

As Figure B.6 shows, we find that the contribution of older individuals to our slack measure is relatively acyclical but has been rising steadily since the Great Recession. We also find increases in the contribution of the college educated (driven primarily by a rise in the population's college share) and we find that cyclicality is concentrated among men and those with less than a college degree. Consequently, demographics are a key contributor to movements in the AHG measure. 
Table A.1. Desired Hours and Gaps by Demographics \& Labor Force Groups Used in Estimation

\begin{tabular}{|c|c|c|c|c|}
\hline Labor Force Status & Description & $N$ & Desired Hours & $\begin{array}{c}\text { Adjusted Hours } \\
\text { Gap }\end{array}$ \\
\hline \multirow{10}{*}{$\begin{array}{l}\text { Employed FT, } \\
\text { single job }\end{array}$} & Male, 18-24, all education & 28 & $\begin{array}{l}41.16 \\
(1.53)\end{array}$ & $\begin{array}{c}0.74 \\
(0.39)\end{array}$ \\
\hline & Male, $25-54,<$ College & 457 & $\begin{array}{l}37.41 \\
(0.62)\end{array}$ & $\begin{array}{c}0.39 \\
(0.10)\end{array}$ \\
\hline & Male, $25-54, \geq$ College & 914 & $\begin{array}{l}38.85 \\
(0.41)\end{array}$ & $\begin{array}{c}0.24 \\
(0.08)\end{array}$ \\
\hline & Male, $55+,<$ College & 214 & $\begin{array}{l}36.36 \\
(0.85)\end{array}$ & $\begin{array}{c}0.20 \\
(0.08)\end{array}$ \\
\hline & Male, $55+, \geq$ College & 261 & $\begin{array}{l}39.16 \\
(0.75)\end{array}$ & $\begin{array}{c}0.31 \\
(0.17)\end{array}$ \\
\hline & Female, $18-24$, all education & 41 & $\begin{array}{l}30.40 \\
(1.97)\end{array}$ & $\begin{array}{c}0.09 \\
(0.08)\end{array}$ \\
\hline & Female, 25-54, < College & 434 & $\begin{array}{l}34.22 \\
(0.59)\end{array}$ & $\begin{array}{c}0.61 \\
(0.10)\end{array}$ \\
\hline & Female, 25-54, $\geq$ College & 678 & $\begin{array}{l}34.51 \\
(0.49)\end{array}$ & $\begin{array}{c}0.33 \\
(0.09)\end{array}$ \\
\hline & Female, $55+,<$ College & 153 & $\begin{array}{l}33.37 \\
(1.10)\end{array}$ & $\begin{array}{c}0.69 \\
(0.24)\end{array}$ \\
\hline & Female, $55+, \geq$ College & 135 & $\begin{array}{l}35.22 \\
(1.05)\end{array}$ & $\begin{array}{c}0.60 \\
(0.34)\end{array}$ \\
\hline \multirow{6}{*}{$\begin{array}{l}\text { Employed FT, } \\
\text { multiple jobs }\end{array}$} & Male, $18-54,<$ College & 88 & $\begin{array}{l}38.12 \\
(1.48)\end{array}$ & $\begin{array}{c}0.17 \\
(0.10)\end{array}$ \\
\hline & Male, $18-54, \geq$ College & 137 & $\begin{array}{l}37.34 \\
(1.24)\end{array}$ & $\begin{array}{c}0.00 \\
(0.00)\end{array}$ \\
\hline & Male, 55+, all education & 78 & $\begin{array}{l}41.60 \\
(1.93)\end{array}$ & $\begin{array}{c}0.00 \\
(0.00)\end{array}$ \\
\hline & Male, $18-54,<$ College & 117 & $\begin{array}{l}37.06 \\
(1.46)\end{array}$ & $\begin{array}{c}0.08 \\
(0.07)\end{array}$ \\
\hline & Male, $18-54, \geq$ College & 172 & $\begin{array}{l}34.74 \\
(1.27)\end{array}$ & $\begin{array}{c}0.13 \\
(0.07)\end{array}$ \\
\hline & Male, 55+, all education & 63 & $\begin{array}{l}36.83 \\
(1.84) \\
\end{array}$ & $\begin{array}{c}0.15 \\
(0.20) \\
\end{array}$ \\
\hline \multirow{7}{*}{$\begin{array}{l}\text { Employed PT, } \\
\text { single job }\end{array}$} & Male, 18-54, all education & 85 & $\begin{array}{l}26.96 \\
(1.41)\end{array}$ & $\begin{array}{c}6.78 \\
(0.93)\end{array}$ \\
\hline & Male, $55+,<$ College & 86 & $\begin{array}{l}20.65 \\
(1.14)\end{array}$ & $\begin{array}{c}2.79 \\
(0.70)\end{array}$ \\
\hline & Male, $55+, \geq$ College & 125 & $\begin{array}{l}19.91 \\
(0.94)\end{array}$ & $\begin{array}{c}2.41 \\
(0.46)\end{array}$ \\
\hline & Female, $18-54,<$ College & 102 & $\begin{array}{l}27.54 \\
(1.06)\end{array}$ & $\begin{array}{c}5.28 \\
(0.74)\end{array}$ \\
\hline & Female, 18-54, $\geq$ College & 105 & $\begin{array}{l}25.46 \\
(1.06)\end{array}$ & $\begin{array}{c}4.69 \\
(0.71)\end{array}$ \\
\hline & Female, $55+,<$ College & 81 & $\begin{array}{l}21.78 \\
(1.15)\end{array}$ & $\begin{array}{c}2.02 \\
(0.51)\end{array}$ \\
\hline & Female, $55+, \geq$ College & 81 & $\begin{array}{l}19.11 \\
(1.17)\end{array}$ & $\begin{array}{c}2.74 \\
(0.72)\end{array}$ \\
\hline
\end{tabular}

(continued on next page) 
Table A.1. (continued)

\begin{tabular}{|c|c|c|c|c|}
\hline Labor Force Status & Description & $\mathbf{N}$ & Desired Hours & $\begin{array}{c}\text { Adjusted Hours } \\
\text { Gap }\end{array}$ \\
\hline \multirow{2}{*}{$\begin{array}{l}\text { Employed PT, } \\
\text { multiple jobs }\end{array}$} & Male, all ages, all education & 104 & $\begin{array}{l}33.00 \\
(1.58)\end{array}$ & $\begin{array}{c}1.14 \\
(0.45)\end{array}$ \\
\hline & Female, all ages, all education & 142 & $\begin{array}{l}25.52 \\
(1.16)\end{array}$ & $\begin{array}{c}1.49 \\
(0.36)\end{array}$ \\
\hline \multirow{2}{*}{$\begin{array}{l}\text { Unemployed } \\
\leq 6 \text { months }\end{array}$} & Male, all ages, all education & 50 & $\begin{array}{l}39.66 \\
(1.30)\end{array}$ & $\begin{array}{l}39.66 \\
(1.30)\end{array}$ \\
\hline & Female, all ages, all education & 77 & $\begin{array}{l}33.73 \\
(1.14) \\
\end{array}$ & $\begin{array}{l}33.73 \\
(1.14) \\
\end{array}$ \\
\hline \multirow{2}{*}{$\begin{array}{l}\text { Unemployed } \\
>6 \text { months }\end{array}$} & Male, all ages, all education & 35 & $\begin{array}{l}36.71 \\
(1.44)\end{array}$ & $\begin{array}{l}36.71 \\
(1.44)\end{array}$ \\
\hline & Female, all ages, all education & 39 & $\begin{array}{l}33.76 \\
(1.55)\end{array}$ & $\begin{array}{l}33.76 \\
(1.55)\end{array}$ \\
\hline \multirow{2}{*}{ OLF, Want Work } & Male, all ages, all education & 22 & $\begin{array}{l}27.15 \\
(2.13)\end{array}$ & $\begin{array}{l}27.15 \\
(2.13)\end{array}$ \\
\hline & Female, all ages, all education & 30 & $\begin{array}{l}30.58 \\
(2.41) \\
\end{array}$ & $\begin{array}{l}30.58 \\
(2.41) \\
\end{array}$ \\
\hline \multirow{4}{*}{ OLF, Retired } & Male, all ages, $<$ College & 351 & $\begin{array}{l}11.50 \\
(0.66)\end{array}$ & $\begin{array}{l}11.50 \\
(0.66)\end{array}$ \\
\hline & Male, all ages, $\geq$ College & 422 & $\begin{array}{l}11.30 \\
(0.60)\end{array}$ & $\begin{array}{l}11.30 \\
(0.60)\end{array}$ \\
\hline & Female, all ages, $<$ College & 284 & $\begin{array}{l}10.91 \\
(0.64)\end{array}$ & $\begin{array}{l}10.91 \\
(0.64)\end{array}$ \\
\hline & Female, all ages, $\geq$ College & 212 & $\begin{array}{c}8.89 \\
(0.70)\end{array}$ & $\begin{array}{c}8.89 \\
(0.70)\end{array}$ \\
\hline \multirow{4}{*}{ OLF, Other } & Male, $18-54$, all education & 95 & $\begin{array}{l}15.99 \\
(1.58)\end{array}$ & $\begin{array}{l}15.99 \\
(1.58)\end{array}$ \\
\hline & Male, $55+$ all education & 87 & $\begin{array}{l}13.45 \\
(1.51)\end{array}$ & $\begin{array}{l}13.45 \\
(1.51)\end{array}$ \\
\hline & Female, $18-54$, all education & 253 & $\begin{array}{l}16.83 \\
(0.84)\end{array}$ & $\begin{array}{l}16.83 \\
(0.84)\end{array}$ \\
\hline & Female, 55+ all education & 113 & $\begin{array}{l}11.84 \\
(1.15)\end{array}$ & $\begin{array}{l}11.84 \\
(1.15)\end{array}$ \\
\hline
\end{tabular}

Notes: Sample is all individuals in the SCE Job Search supplement aged 18-79 pooled across its 2013-2018 surveys. The desired hours gap is adjusted so that desired hours equal total work hours for employed individuals whose reported desired hours would otherwise imply a negative hours gap. Standard errors are in parentheses. 
Table B.1. Desired Hours Gaps by Additional Demographics and Broad Labor Force Status

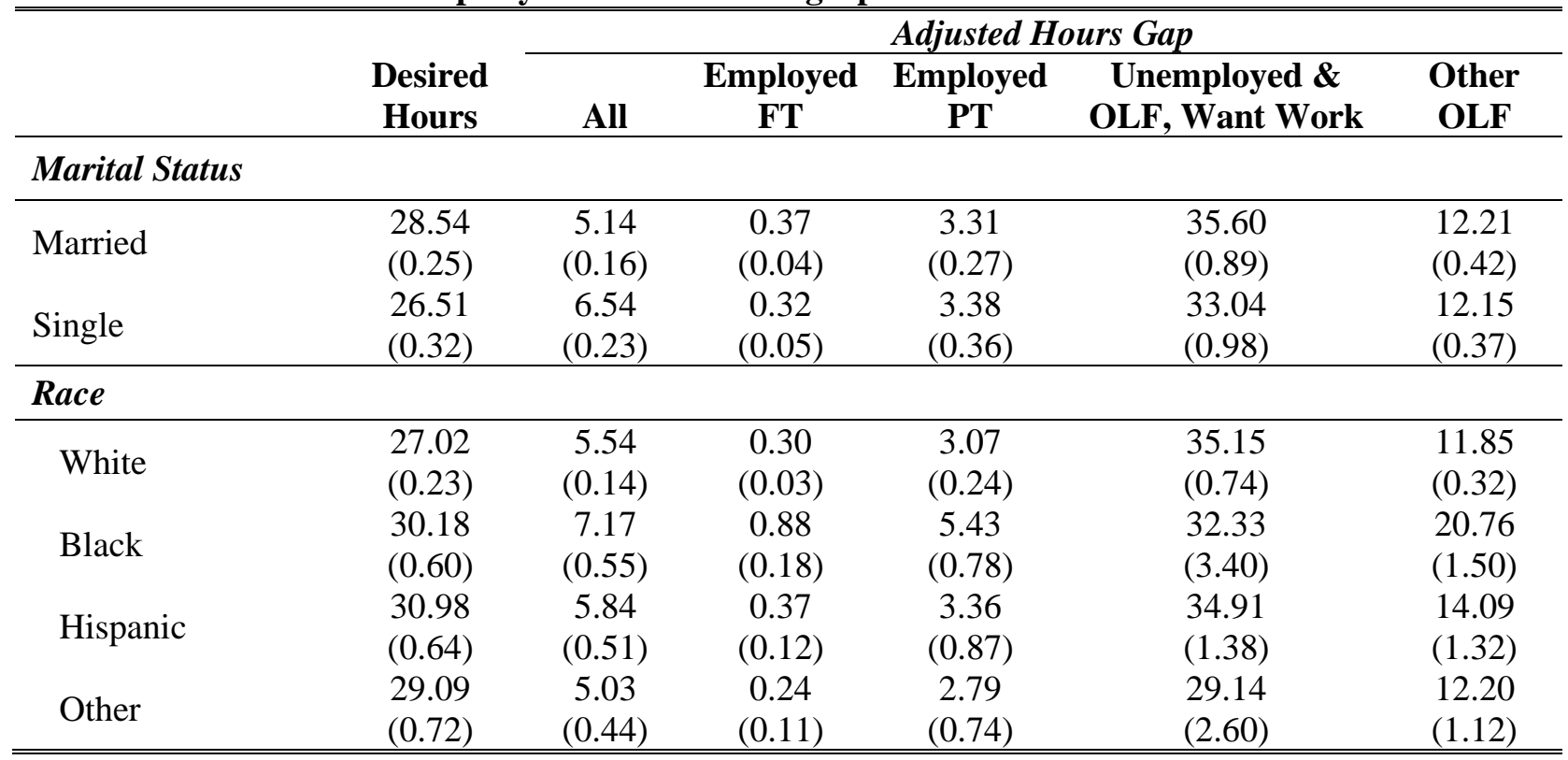

Notes: Sample is all individuals in the SCE Job Search supplement aged 18-79 pooled across its 2013-2018 surveys. The desired hours gap is adjusted so that desired hours equal total work hours for employed individuals whose reported desired hours would otherwise imply a negative hours gap. Standard errors are in parentheses.

Table B.2. Job-to-Job Transitions by Type of New Job

\begin{tabular}{|c|c|c|c|c|c|c|c|}
\hline \multirow[b]{2}{*}{$\begin{array}{l}\text { Prior Month's } \\
\text { LFS }\end{array}$} & \multicolumn{4}{|c|}{ Job-to-Job Transition to... } & \multirow[b]{2}{*}{$\begin{array}{c}\text { JF Rate } \\
\text { (new main job) }\end{array}$} & \multirow[b]{2}{*}{$\begin{array}{c}\text { Added } 2^{\text {nd }} \\
\text { Job }\end{array}$} & \multirow[b]{2}{*}{$\begin{array}{c}\text { JF Rate } \\
\text { (new or } 2^{\text {nd }} \text { job) }\end{array}$} \\
\hline & $E^{f s}$ & $E^{f m}$ & $E^{p s}$ & $E^{p m}$ & & & \\
\hline $\begin{array}{l}\text { Employed FT, } \\
\text { single job }\end{array}$ & .017 & .001 & .002 & .000 & .020 & .013 & .033 \\
\hline $\begin{array}{l}\text { Employed FT, } \\
\text { multi job }\end{array}$ & .014 & .017 & .008 & .002 & .040 & --- & .040 \\
\hline $\begin{array}{l}\text { Employed, PT, } \\
\text { single job }\end{array}$ & .011 & .003 & .019 & .001 & .034 & .020 & .054 \\
\hline $\begin{array}{l}\text { Employed PT, } \\
\text { multiple job }\end{array}$ & .011 & .014 & .032 & .020 & .076 & --- & .076 \\
\hline All Employed & .016 & .002 & .005 & .001 & .024 & .013 & .037 \\
\hline
\end{tabular}

Note: Table reports monthly job-to-job transition rates between the listed employment states and the implied jobfinding rates, pooled across all months between January 1994 and December 2018. Job-to-job transition rates refer to individuals who reported having a new "main" job in the current month. "Added 2 nd job" refers to individuals who remained at the same main job but switched from being a single jobholder to a multiple jobholder. The final column includes these individuals in the overall job finding rate of each employment category. Sample is all individuals aged 18 to 79 in the Current Population Survey. 
Figure B.1. Histograms of Adjusted Desired Hours Gaps by Detailed Labor Force Status

Employed FT, Single Job

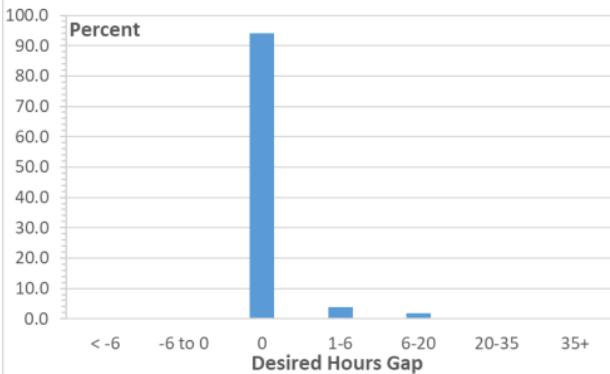

Employed PT, Multiple Jobs

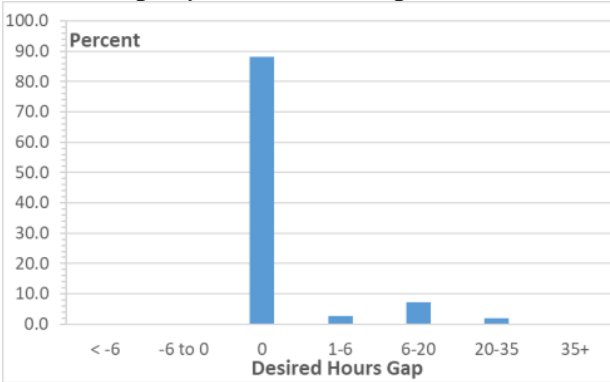

OLF, Want Work

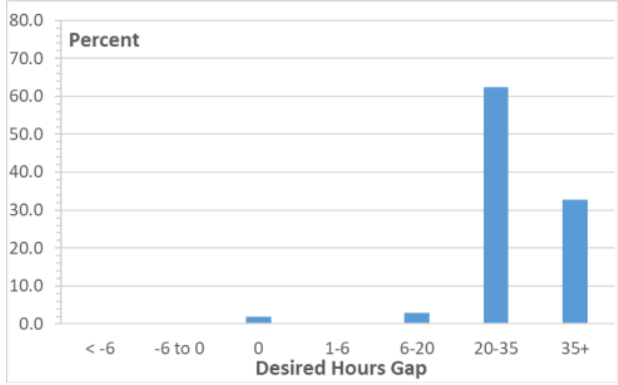

Employed FT, Multiple Jobs

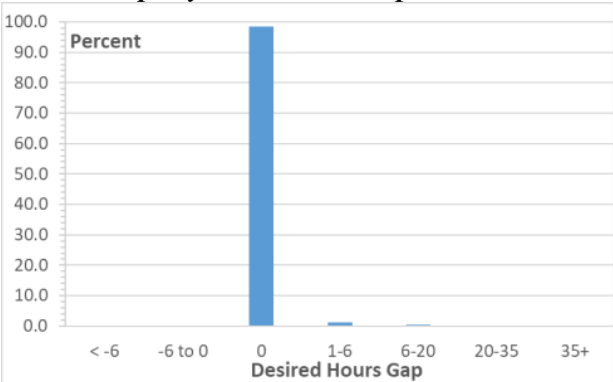

Unemployed $\leq 6$ Months

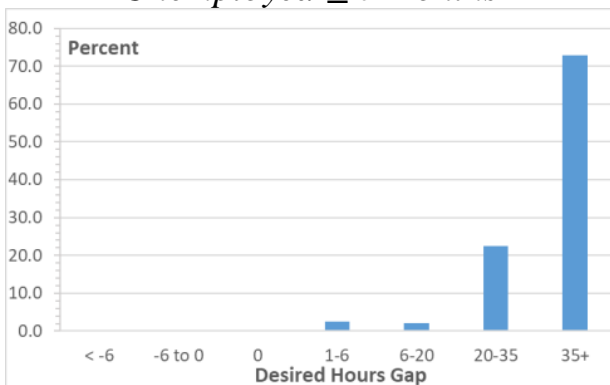

OLF, Retired

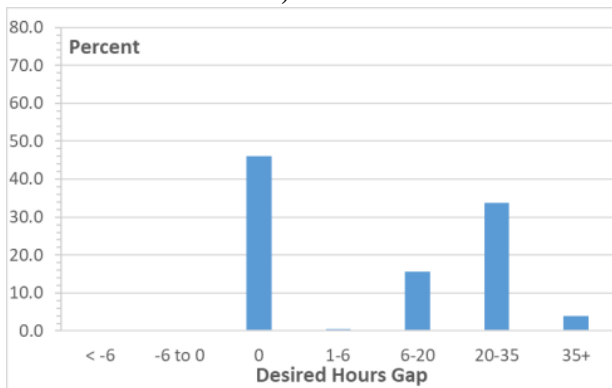

Employed PT, Single Job

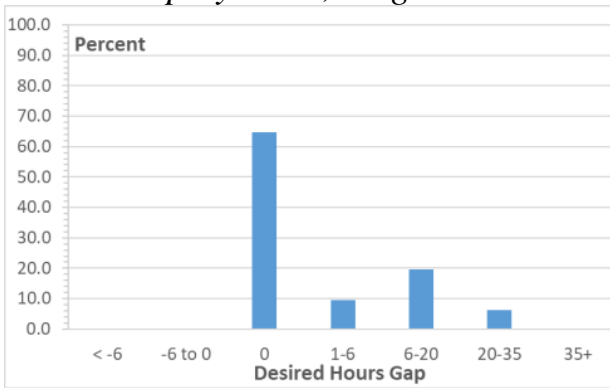

Unemployed > 6 Months

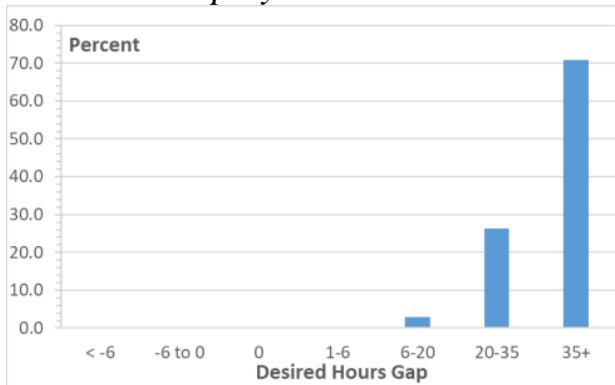

OLF, Other

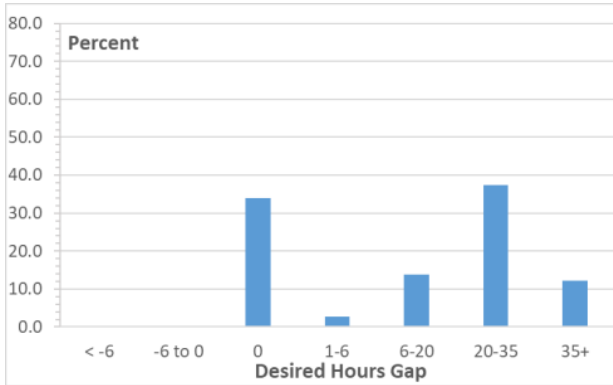

Notes: Histograms report the desired work hours gaps separately by each listed labor force state and include a separate category for those with a gap of exactly zero. Desired hours for the employed adjust negative implied hours gaps for the employed to zero. Sample is the pooled SCE Job Search supplement aged 18-79 with nonmissing age, education, gender, marital status, or labor force status data. 
Figure B.2. Relationships between Search Effort and Desired Hours

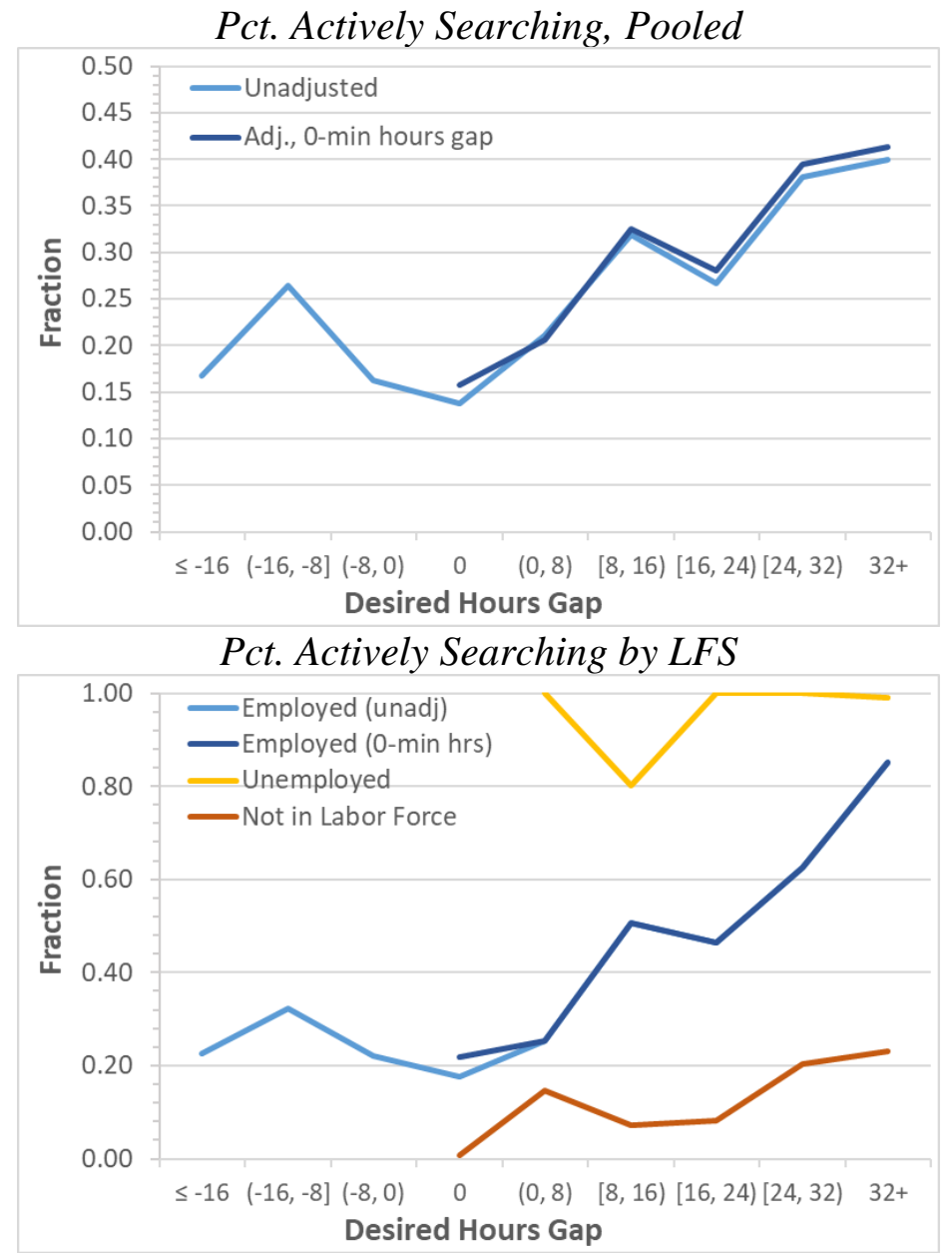

(arcsinh) Mean Applications Sent, Pooled

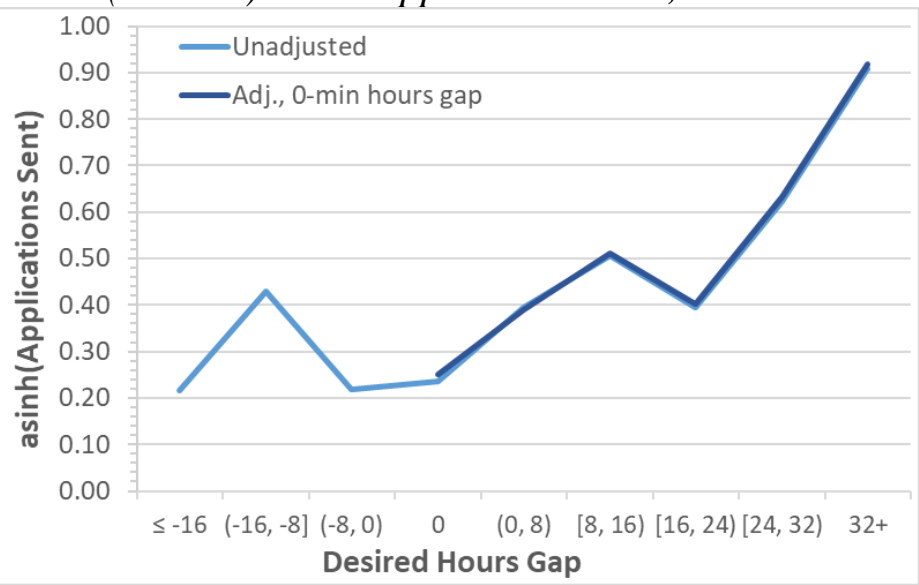

\section{(arcsinh) Mean Applications Sent, by LFS}

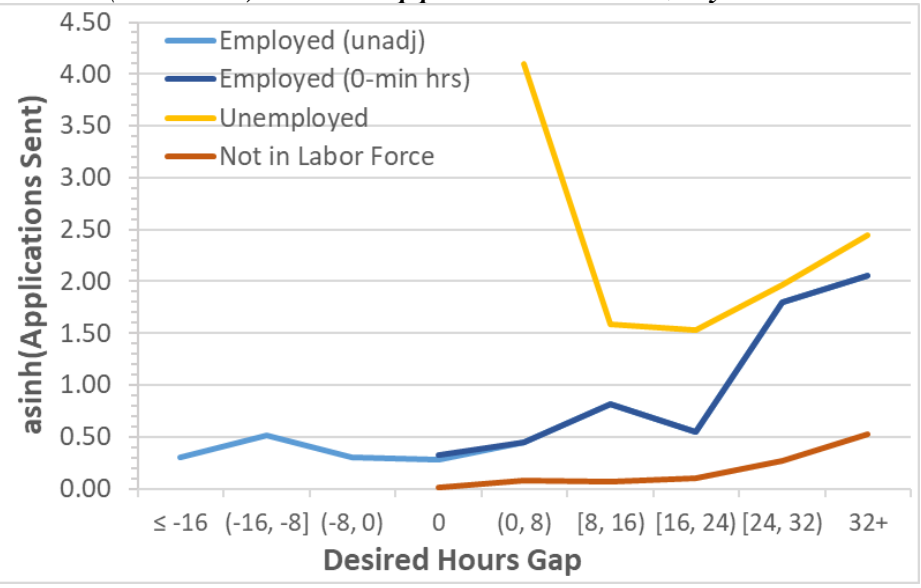

Notes: Estimates report the fraction of individuals who actively searched (left panels) or the number of applications sent (right panels) for all individuals aged 18-85 in the SCE Job Search supplement, pooled across its 2013-2018 surveys. The top panels report the mean search effort measures conditional on broad labor force status (employed, unemployed, or out of the labor force). The bottom panels report the search effort measures separately for each labor force status. 
Figure B.3. The Aggregate Hours Gap, Alternate Estimation Approaches

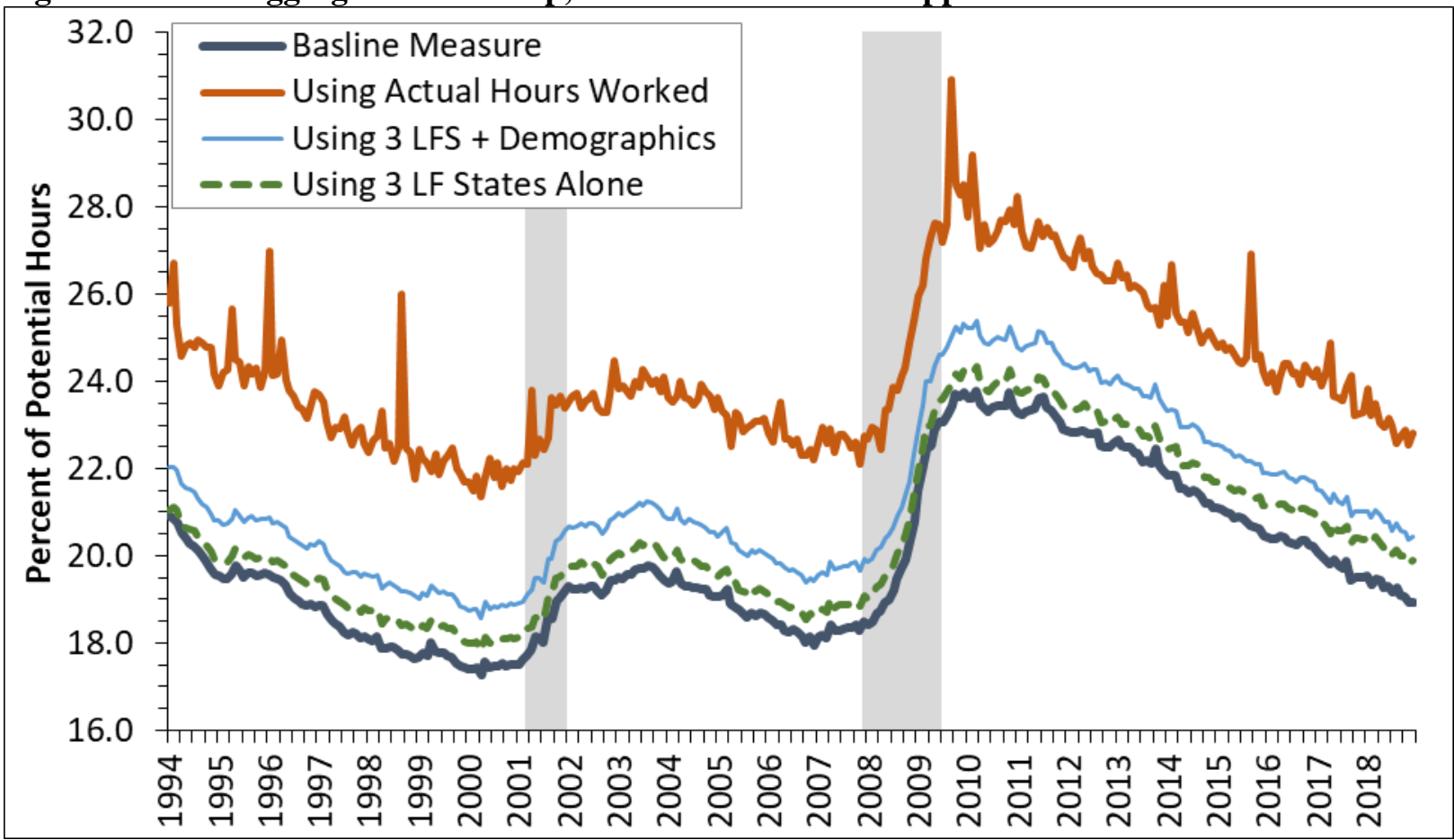

Note: Estimates are for all individuals aged 18-79 from the Current Population Survey. The baseline AHG measure is described in the text. The estimates with actual hours use actual hours worked in the prior week rather than usual hours worked, as reported in the CPS. The three-state LFS measures only use mean desired hours estimates that are disaggregated by employment, unemployment, or being out of the labor force, with and without additional disaggregation by demographics within each labor market state. See text for details. 


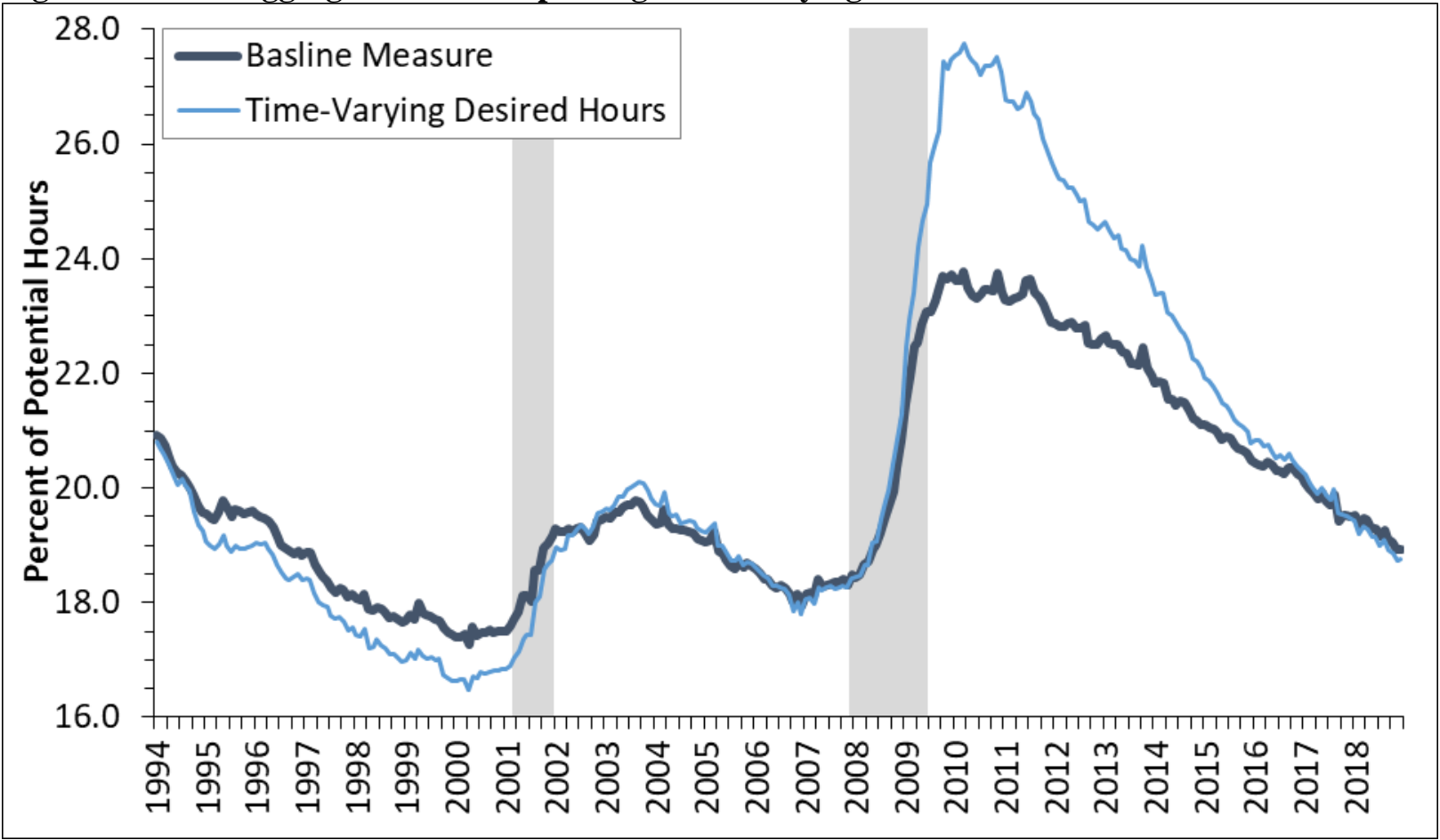

Note: Estimates are for all individuals aged 18-79 from the Current Population Survey. The baseline AHG measure is described in the text. The estimates with time-varying desired hours use estimates derived from an out-of-sample prediction based on demographics, detailed labor force status, hours worked, and labor market tightness variables. See text for details.

Figure B.5. Unemployment vs. the Aggregate Hours Gap for Prime-Aged Males

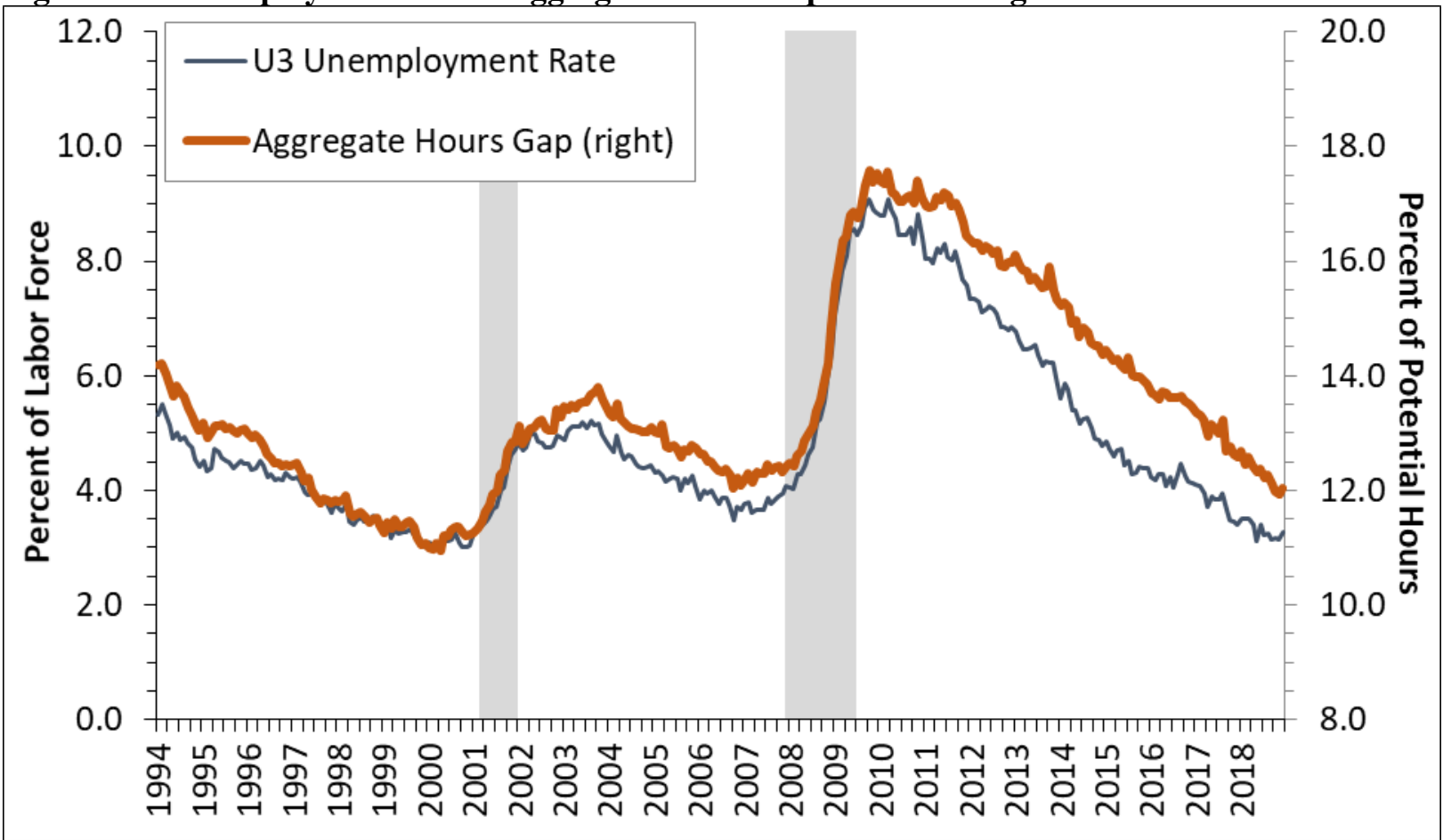

Note: Estimates are for all males aged 25-54 from the Current Population Survey. The U3 measure is the official BLS unemployment rate measure. The AHG measure is our baseline measure described in the text. 
Figure B.6. Contributions to the Aggregate Hours Gap by Demographics

(a) Age

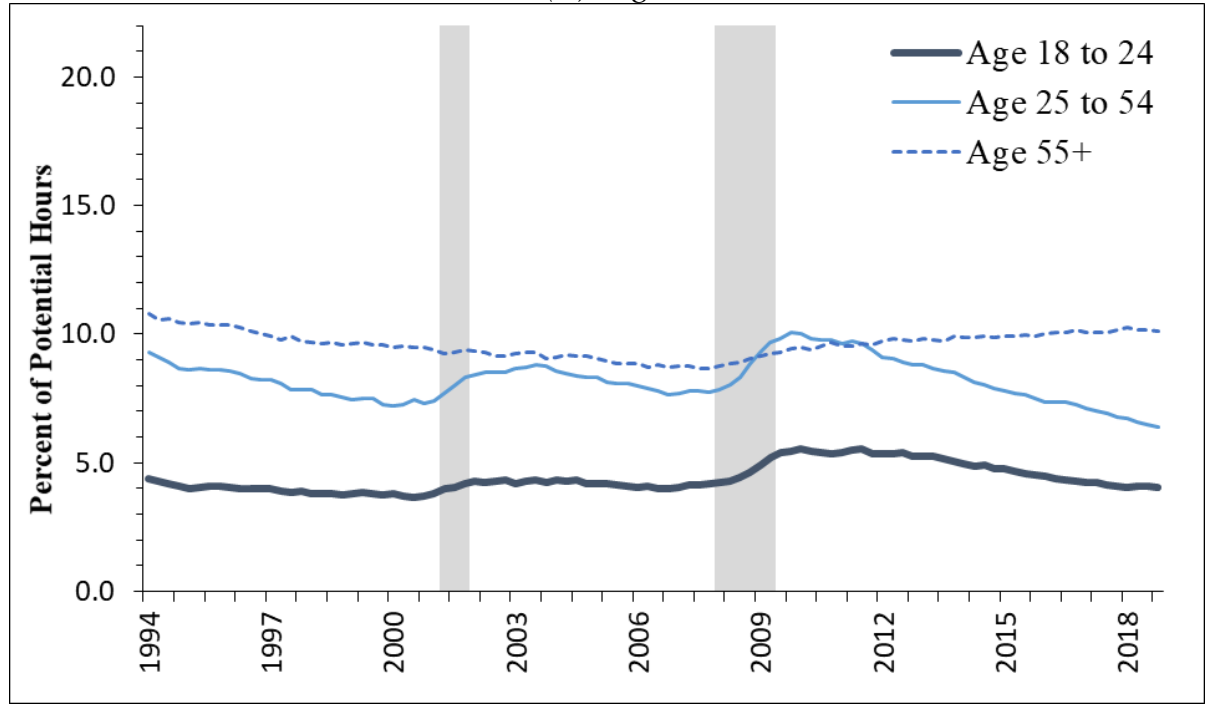

(b) Gender

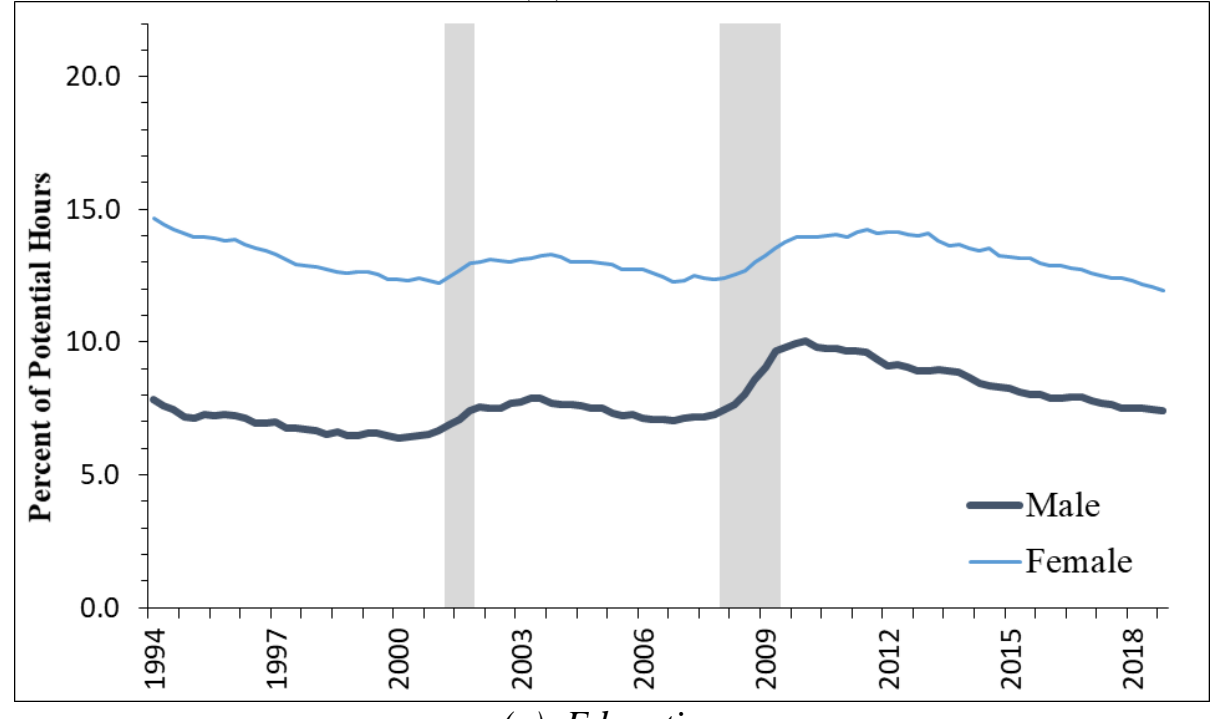

(c) Education

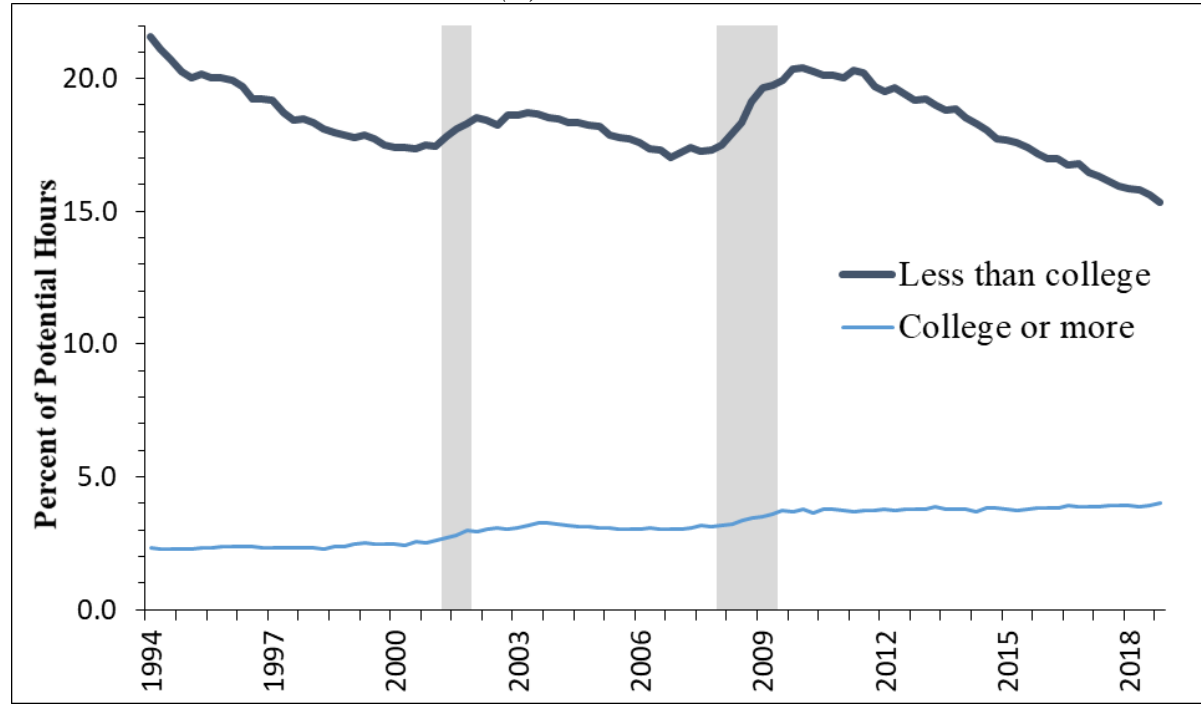

Note: Estimates are the contribution of each listed demographic subgroup to the overall AHG measure. The contributions are equal to their population share multiplied by the within-group AHG estimate. See text for details. 